ARTICLE

\title{
Integrin- $\alpha_{V}$-mediated activation of TGF- $\beta$ regulates anti-tumour CD8 $T$ cell immunity and response to PD-1 blockade
}

Ines Malenica1, Julien Adam,8, Stéphanie Corgnac (1) 1,8, Laura Mezquita2,6,7, Edouard Auclin³, Isabelle Damei', Laetitia Grynszpan ${ }^{1}$, Gwendoline Gros ${ }^{1}$, Vincent de Montpréville (1) ${ }^{1,4}$, David Planchard ${ }^{2}$, Nathalie Théret (1) ${ }^{5}$, Benjamin Besse $^{2} \&$ Fathia Mami-Chouaib (1) ${ }^{1 凶}$

TGF- $\beta$ is secreted in the tumour microenvironment in a latent, inactive form bound to latency associated protein and activated by the integrin $\alpha_{V}$ subunit. The activation of latent TGF- $\beta$ by cancer-cell-expressed $\alpha_{V}$ re-shapes the tumour microenvironment, and this could affect patient responses to PD-1-targeting therapy. Here we show, using multiplex immunofluorescence staining in cohorts of anti-PD-1 and anti-PD-L1-treated lung cancer patients, that decreased expression of cancer cell $\alpha_{V}$ is associated with improved immunotherapy-related, progression-free survival, as well as with an increased density of $\mathrm{CD} 8^{+} \mathrm{CD} 103^{+}$tumourinfiltrating lymphocytes. Mechanistically, tumour $\alpha_{\vee}$ regulates CD8 T cell recruitment, induces CD103 expression on activated $\mathrm{CD}^{+} \mathrm{T}$ cells and promotes their differentiation to granzyme B-producing $\mathrm{CD}_{103}{ }^{+} \mathrm{CD} 69^{+}$resident memory $\mathrm{T}$ cells via autocrine TGF- $\beta$ signalling. Thus, our work provides the underlying principle of targeting cancer cell $\alpha_{\vee}$ for more efficient PD-1 checkpoint blockade therapy.

\footnotetext{
${ }^{1}$ INSERM UMR 1186, Integrative Tumour Immunology and Immunotherapy, Gustave Roussy, Fac. de Médecine-Univ. Paris-Sud, Université Paris-Saclay, Villejuif, France. ${ }^{2}$ Department of Cancer Medicine, Gustave Roussy Cancer Campus, Institut d'Oncologie Thoracique, Gustave Roussy, Université ParisSaclay, Villejuif, France. ${ }^{3}$ Medical and Thoracic Oncology Department, Hôpital Européen Georges Pompidou, AP-HP, Paris, France. ${ }^{4}$ Hôpital MarieLannelongue, Service d'Anatomie Pathologique, Le-Plessis-Robinson, France. ${ }^{5}$ Univ Rennes, Inserm, EHESP, Irset-UMR-S1085, Rennes, France. ${ }^{6}$ Present address: Laboratory of Translational Genomics and Targeted Therapeutics in Solid Tumours, August Pi i Sunyer Biomedical Research Institute (IDIBAPS), Barcelona, Spain. ${ }^{7}$ Present address: Medical Oncology Department, Hospital Clínic, Barcelona, Spain. ${ }^{8}$ These authors contributed equally: Julien Adam,

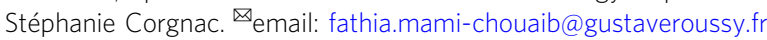


mmunotherapy targeting the $\mathrm{T}$ cell inhibitory receptor programmed death-1 (PD-1) and its ligand PD-L1 holds promise in lung cancer treatment ${ }^{1}$. However, given the limited therapeutic benefit of anti-PD-(L)1 antibodies as single agents, it is crucial to identify the immune mechanisms involved in tumour resistance to immune checkpoint blockade (ICB) and develop more effective combinatorial approaches. Resistance to ICB has been associated with defects in genes relating to antigen presentation by major histocompatibility complex class I (MHC-I) molecules to $\mathrm{CD}^{+} \mathrm{T}$ lymphocytes ${ }^{2-4}$, mutations in the Janus kinase (JAK) $1 /$ JAK2 and interferon (IFN) signalling pathways $^{2,5,6}$, and clonal deletion of tumour-specific $\mathrm{T}$ cells ${ }^{7}$. Accumulating evidence indicates that tumour regression following $\mathrm{PD}-1$ blockade requires pre-existing $\mathrm{CD}^{+}{ }^{+} \mathrm{T}$ lymphocytes that are negatively regulated by $\mathrm{PD}-1$-mediated resistance ${ }^{8}$. Consequently, tumours that are weakly infiltrated by $\mathrm{CD}^{+}$ $\mathrm{T}$ cells are unlikely to respond to such therapeutic interventions. The quality of $\mathrm{CD}^{+}$tumour-infiltrating lymphocytes (TIL), especially their reactivity toward the cognate target, is also directly associated with the efficacy of anti-PD-1. In this regard, expression of PD-1 on CD8 ${ }^{+}$TIL appeared to define clonally expanded tumour neoantigen-specific $\mathrm{T}$ cells detected in cancer patients ${ }^{9,10}$. More recently, expression of CD103 $\left(\alpha_{\mathrm{E}}(\mathrm{CD} 103) \beta_{7}\right)$ integrin, together with CD39 and CD137 (4-1BB), has been reported to identify truly tumour-reactive $\mathrm{CD}^{+} \mathrm{T}$ cells in human solid tumours ${ }^{11,12}$.

CD103 delineates a subtype of $\mathrm{CD}^{+}$resident memory $\mathrm{T}$ $\left(\mathrm{T}_{\mathrm{RM}}\right)$ cells, which stably reside in many human solid tumours where they likely orchestrate a local immune response to cancer cells $^{13}$. Human non-small-cell lung cancer (NSCLC) CD $103{ }^{+}{ }^{C D} 8{ }^{+} \mathrm{T}_{\mathrm{RM}}$ cells frequently express the activation marker CD69 and a panel of $\mathrm{T}$ cell inhibitory receptors, including $\mathrm{PD}-1^{14}$. They are enriched with tumour-reactive $\mathrm{T}$ lymphocytes able to kill autologous tumour cells upon blockade of PD-1 with neutralizing antibodies ${ }^{15}$. This $\mathrm{CD} 103^{+} \mathrm{CD} 8^{+} \mathrm{T}_{\mathrm{RM}}$ subset emerges as a predictive marker of survival in several cancers, including NSCLC $^{15-18}$. CD103 ${ }^{+} \mathrm{CD} 8^{+} \mathrm{T}_{\mathrm{RM}}$ expands during anti-PD-1 immunotherapy, and their accumulation in tumours is associated with the improved outcome of anti-PD-(L)1-treated patients $14,18,19$.

It is now widely recognized that induction of CD103 on activated $\mathrm{CD}^{+} \mathrm{T}$ lymphocytes and persistence of $\mathrm{CD}^{+} 03^{+} \mathrm{CD}^{+}$ $\mathrm{T}_{\mathrm{RM}}$ in epithelial tissues requires transforming growth factor-beta (TGF- $\beta$ ). TGF- $\beta$ is important for tissue remodelling and repair at sites of inflammation ${ }^{20}$, but is also an immunosuppressive mediator used by malignant cells to escape from the immune system $^{21,22}$. This cytokine is secreted in the tumour microenvironment (TME) in its inactive (latent) form bound to latency-associated protein (LAP), and is activated by metalloproteinases (MMP) 23,24 and RGD-binding integrins, such as $\alpha_{\mathrm{V}} \beta_{6}$ and $\alpha_{V} \beta_{8}{ }^{25,26}$. It has been reported that $\alpha_{V} \beta_{8}$-expressing tumours evade host immunity by activating latent TGF- $\beta$ on adjacent immune cells ${ }^{27}$. In contrast, activation of TGF- $\beta$ by $\alpha_{V} \beta_{8}$ integrin on tumour-infiltrating dendritic cells (DC) induced CD103 expression on $\mathrm{CD}^{+} \mathrm{T}$ cells resulting in inhibition of cancer progression ${ }^{28}$. Thus, the role of $\alpha_{V}$ integrins in shaping the tumour ecosystem and regulating the anti-tumour immune response is controversial and needs to be better understood.

Here, we show that increased tumour $\alpha_{V}$ expression is associating with worse immunotherapy-related progression-free survival (PFS) in anti-PD-(L)1-treated NSCLC patients, which correlates with the decreased density of $\mathrm{CD} 103^{+} \mathrm{CD} 8{ }^{+} \mathrm{TIL}$. In vivo therapeutic blockade of $\mathrm{PD}-1$ in a mouse model greatly improves growth control of $\alpha_{\mathrm{V}}$-knockout tumours via a mechanism involving increased tumour infiltration by activated tumour-specific $\mathrm{CD} 03^{+} \mathrm{CD}^{+} \mathrm{T}$ cells. Thus, targeting tumour $\alpha_{V}$ integrin to prevent endogenous TGF- $\beta$ maturation is a promising approach for more effective ICB.

\section{Results}

Tumour $\alpha_{\mathrm{V}}$ expression levels influence response to anti-PD-(L) 1. To investigate the impact of tumour $a_{V}$ expression on survival in patients with lung cancer, we used a retrospective cohort of 113 patients with treatment-naïve early-stage NSCLC ${ }^{15}$. Tumour sections from formalin-fixed, paraffin-embedded samples were stained with anti- $\alpha_{\mathrm{V}}$ monoclonal antibodies $(\mathrm{mAb})$ and evaluated by immunohistochemistry (IHC) for the expression of the integrin in epithelial tumour regions. Variability in tumour $a_{V}$ expression was seen, with $11 \%$ of tumours displaying a $\alpha_{V}$ high profile and $89 \%$ displaying a $a_{V}$ low profile, among which $36 \%$ were negative for $\alpha_{V}$ expression ( $a_{V}{ }^{\text {neg }}$ ) (Fig. 1a). We did not find any significant difference in overall survival (OS) of patients bearing $\alpha_{\mathrm{V}}$ low and $\alpha_{\mathrm{V}}$ high tumours (Fig. 1b), with a hazard ratio $(\mathrm{HR})=1.05,95 \%$ confidence interval (CI) $0.38-2.97$, and median OS of 68 months (95\% CI 62.9-not reached). Similar nonsignificant results were obtained with public TCGA datasets from therapy-naïve stage I lung cancers (Supplementary Fig. 1a). These data indicate that tumour $\alpha_{\mathrm{V}}$ expression does not influence treatment-naïve patient survival.

We then examined the consequence of tumour $a_{V}$ levels on survival in patients treated with ICB. We established a retrospective cohort (cohort 1) of 106 patients with advanced NSCLC treated with a single-agent anti-PD-(L)1 as a second-line treatment (Supplementary Table 1$)^{14}$. Association of $\alpha_{V}$ expression in epithelial tumour regions with progression-free survival (PFS) after the first immunotherapy administration was assessed. Notably, chemotherapy and radiation therapy prior to immunotherapy had no significant impact on tumour $\alpha_{V}$ levels (Supplementary Table 1). Patients with $\alpha_{\mathrm{V}}{ }^{\text {low }}$ tumours (including $\left.18 \% \alpha_{V}{ }^{\text {neg }}\right)$ had increased PFS with a $\mathrm{HR}=0.47$ (95\% CI $0.17-0.81, p=0.01$ ) and a median PFS of 8.2 months (Fig. 1c), compared to patients with $\alpha_{\mathrm{V}}$ high tumours ( $16 \%$ of patients), who displayed strongly decreased PFS, with a median PFS of 1.5 months. Association between $\alpha_{\mathrm{V}}$ low tumours and better PFS of anti-PD-(L)1-treated patients was then investigated in a second cohort (cohort 2) of 51 NSCLC (Supplementary Table 2 and Supplementary Fig. 1b) alone and pooled with cohort 1 (Supplementary Fig. 1c) because of the low number $(n=9)$ of $a_{V}$ high tumours in cohort 2. Results showed a trend toward statistical significance for the association between $\alpha_{V}$ low tumours and better PFS in anti-PD-(L)1-treated patients (Supplementary Fig. 1c). In multivariable analysis performed on the pooled cohorts $(n=157)$, there was a trend toward a worse PFS for patients with $\alpha_{\mathrm{V}}$ high tumours $(\mathrm{HR}=1.60,95 \%$ CI $0.98-2.62$, $p=0.06$ ) (Supplementary Table 3 ). Notably, tumours with $a_{\mathrm{V}}$ high expression levels in the cohort 1 were predominant in fastprogressor patients, defined by "early death" occurring during the first 12 weeks after initiating ICB than in long-responder patients, defined by a PFS $>6$ months and OS $>12$ months. Indeed, $30 \%$ of fast-progressors displayed $\alpha_{\mathrm{V}}$ high tumours versus $9 \%$ of longresponders (Fig. 1d). More importantly, quantitative multiplex fluorescent IHC staining using anti-CD8 mAb showed that $\alpha_{\mathrm{V}}$ low tumours were more strongly infiltrated with $\mathrm{CD} 8^{+}$lymphocytes than $\alpha_{V}$ high tumours, with a CD8 cell density ranging from 8 to 2103 cells $/ \mathrm{mm}^{2}$ and a median of 352 cells $/ \mathrm{mm}^{2}$ in $\alpha_{\mathrm{V}}$ low tumours; and from 25 to 436 cells $/ \mathrm{mm}^{2}$ and a median of 176 cells $/ \mathrm{mm}^{2}$ in $a_{\mathrm{V}}$ high tumours $(p=0.046$; Fig. 1e). Similar results were obtained when we pooled cohort 1 and cohort 2 (Supplementary Fig. 1d). Furthermore, multiplex IHC staining with anti-CD8 and antiCD103 mAb showed that the density of $\mathrm{CD}^{+}{ }^{+} \mathrm{CD} 103^{+}$cells was 
a

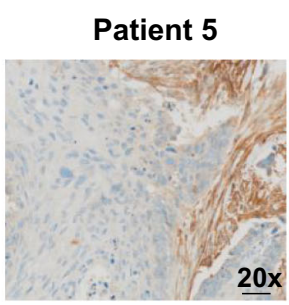

Tumour $\alpha_{v}^{\text {low }}$

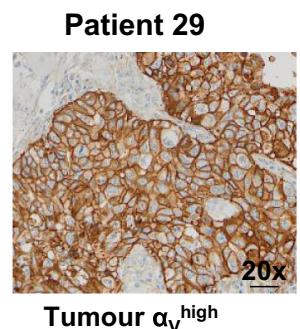

Tumour $\boldsymbol{\alpha}_{\mathrm{v}}^{\text {high }}$

C

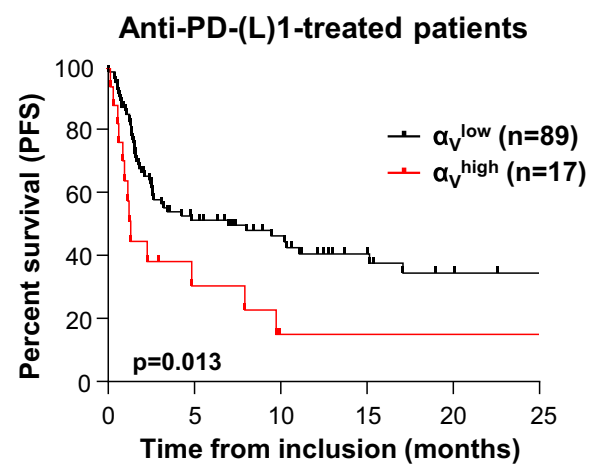

e

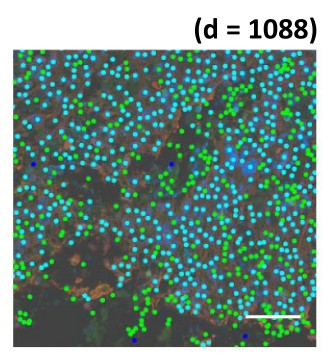

Tumour $\boldsymbol{\alpha}_{\mathrm{v}}^{\text {low }}$

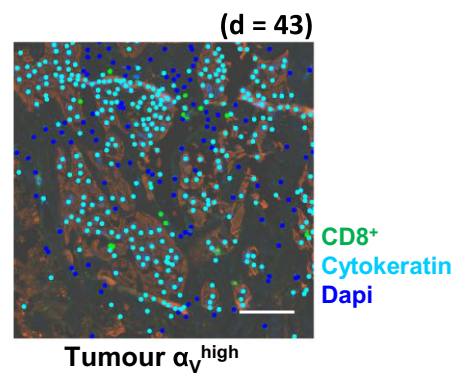

f

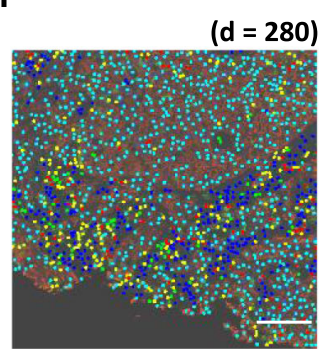

Tumour $\alpha_{v}^{\text {low }}$
Tumour $\alpha_{\mathrm{v}}{ }^{\text {high }}$

$(d=22)$

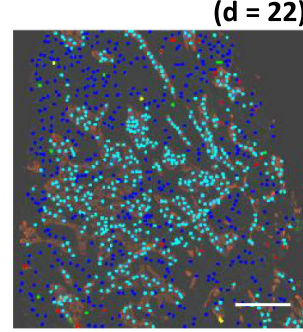

Tumour $\alpha_{\mathrm{v}}^{\text {high }}$ b

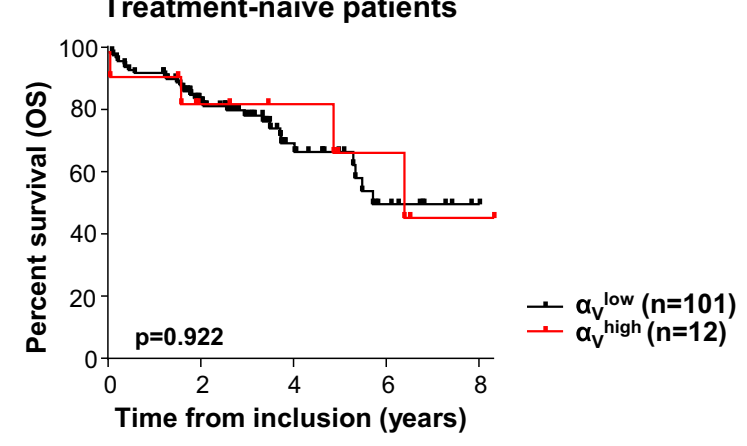

d
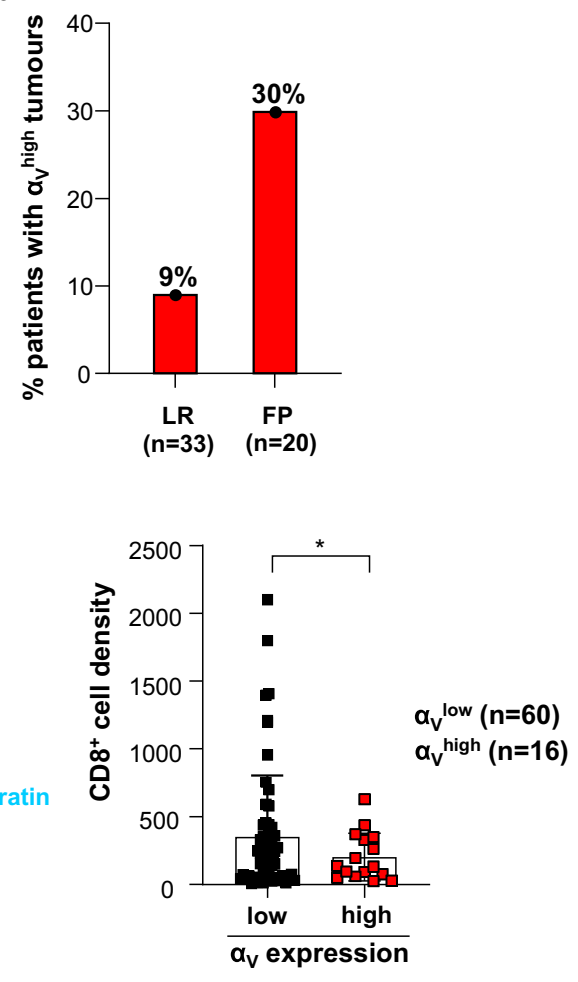

CD103-CD8 ${ }^{+}$ CD103+CD8 CD103+CD8 Cytokeratin Dapi
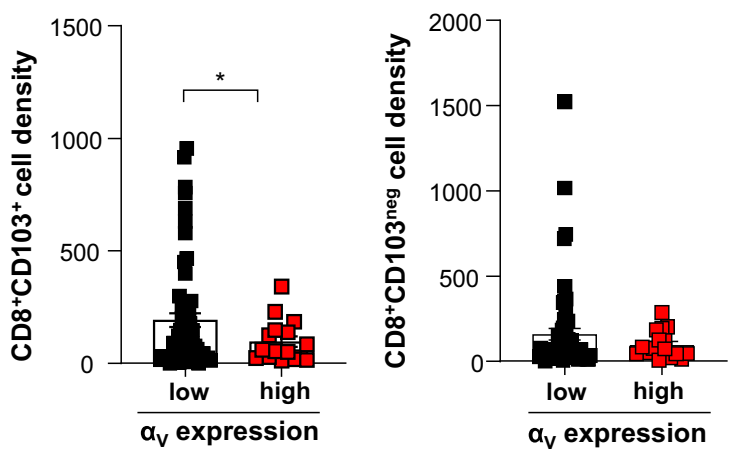

$\alpha_{v}^{\text {low }}(n=60)$
$\alpha_{v}^{\text {high }}(n=16)$

participates in CD8 $\mathrm{T}$ cell exclusion from the TME and differentiation of $\mathrm{CD} 103^{+} \mathrm{T}_{\mathrm{RM}}$ cells.

Integrin $\alpha_{\mathrm{V}}$ on NSCLC cells activates TGF- $\beta$. Next, we investigated the expression of $\alpha_{V}$ in NSCLC tumours ex vivo. Because the $\alpha_{V}$ subunit pairs with $\beta_{6}$ and $\beta_{8}$ subunits to activate TGF- $\beta^{26}$, we first conducted quantitative (q)RT-PCR to evaluate the expression enhanced in tumours with $\alpha_{\mathrm{V}}$ low levels compared to tumours with $\alpha_{V}$ high (Fig. If and Supplementary Fig. 1d). A difference in $\mathrm{CD}^{+} \mathrm{CD} 103^{\text {neg }}$ cell infiltration was observed when we pooled both patient cohorts $(p=0.002$; Supplementary Fig. 1d). These results support the observation that $\alpha_{\mathrm{V}}$ integrin dictates patient response to ICB by regulating tumour infiltration by $\mathrm{CD} 8^{+}$ lymphocytes. They suggest that by activating TGF- $\beta, \alpha_{V}$ 
Fig. 1 Decreased tumour $\boldsymbol{\alpha}_{\mathbf{v}}$ expression correlates with improved anti-PD-(L)1-treated NSCLC patient survival. a Representative IHC images of tumour samples from patients with low and high $\alpha_{V}$ expression in tumour cells. Objective: 20x. b Kaplan-Meier curve of OS for stage I treatment-naïve lung cancer patients according to the $\alpha_{V}$ expression by IHC analysis of FFPE tumours. c Kaplan-Meier curve of PFS of PD-1 blockade-treated patients with tumours harbouring low and high expression of $\alpha_{V}$ integrin. $\mathbf{d}$ Percentages of anti-PD-(L)1-treated patients displaying $\alpha_{V}$ high tumours among longresponders (LR: PFS > 6 months and OS $>12$ months) or fast progressors (FP: defined by "early death" occurring within 12 weeks of treatment initiation). e Representative digital mark-up image of fluorescent IHC of CD8 (green), cytokeratin (turquoise), and dapi (blue) staining in $\alpha_{V}$ low and $\alpha_{V}$ high tumour sections. $d=\mathrm{CD}^{+}$cell density. Left, the density of CD8 $8^{+}$TIL in $\alpha_{\vee}$ low and $\alpha_{\vee}$ high tumours. The numbers of tumours in each group are indicated $\left({ }^{*} p=0.046\right)$. Scale bar, $2 \mathrm{~cm}$. $\mathbf{f}$ Representative digital mark-up image of $\mathrm{CD} 8^{+} \mathrm{CD} 103^{\text {neg }}$ (green), $\mathrm{CD} 8^{+} \mathrm{CD} 103^{+}$(orange), $\mathrm{CD} 8^{-} \mathrm{CD} 103^{+}\left(\right.$red), ${ }^{\mathrm{c} y t o k e r a t i n}$ (turquoise) and dapi (blue) staining in $\alpha_{\vee}{ }^{\text {low }}$ and $\alpha_{\vee}$ high tumour sections. $d=C D 8^{+}$CD103 ${ }^{+}$cell density. Left, the density of $C D 8^{+}$CD103 ${ }^{+}\left({ }^{*} p=0.016\right)$ and $C D 8^{+} C_{103}$ neg $(p=0.120)$ cells in tumour regions of $\alpha_{\vee}$ low and $\alpha_{\vee}$ high tumours. Scale bar, $2 \mathrm{~cm}$. Each symbol represents an individual cell type from tumour samples; horizontal lines correspond to mean \pm standard error of the mean (SEM) (e, f). Data were calculated with the log-rank test $(\mathbf{b}, \mathbf{c})$ and Welch's two-sided $t$-test $(\mathbf{e}, \mathbf{f})$. Source data are provided as a Source Data file.

of ITGAV, ITGB6, and ITGB8 mRNA in 15 freshly resected primary NSCLC. Log scale analyses showed that ITGAV and ITGB8 transcripts were more strongly expressed in four out of 15 tumour samples compared to autologous proximal healthy lung tissues. In contrast, the ITGB6 transcript was much less frequently expressed (Supplementary Fig. 2a). qRT-PCR conducted to evaluate the expression of genes encoding additional $\beta$ subunits that may pair with $\alpha_{\mathrm{V}}$ integrin showed that ITGB1 and ITGB5 mRNA were equally expressed in tumours than in adjacent healthy lungs $(n=15)$ and that ITGB3 was more strongly expressed in two tumours than in healthy lungs (Supplementary Fig. 2b). We then assessed $\alpha_{\mathrm{V}}$ protein expression in 18 additional freshly resected tumours using specific mAb, combined with anti-EpCAM and anti-E-cadherin to delineate integrin expression on epithelial cancer cells (Supplementary Fig. 2c). Multi-parametric immunofluorescence showed variable $a_{\mathrm{V}}$ levels with a mean of $51 \pm 7 \%$ of $\mathrm{EpCAM}^{+} \mathrm{E}$-cadherin ${ }^{+}$tumour cells that expressed the integrin, while only $21 \pm 6 \%$ of non-epithelial EpCAM ${ }^{\text {negE-cadherin }}{ }^{\text {neg }}$ cells were $a_{\mathrm{V}}{ }^{+}$(Fig. 2a). Moreover, $37 \pm 6 \%$ of EpCAM ${ }^{+}$E-cadherin ${ }^{+}$ tumour cells expressed $\alpha_{\mathrm{V}}$ in association with $\beta_{6}$, while only $14 \% \pm$ $4 \%$ of non-epithelial $\alpha_{V}{ }^{+}$EpCAM ${ }^{\text {negE-cadherin }}{ }^{\text {neg }}$ cells were $\beta_{6}{ }^{+}$,

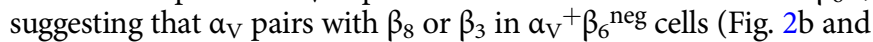
Supplementary Fig. 2c). It should be noted that $\mathrm{CD} 4^{+}$and $\mathrm{CD} 8^{+}$ $\mathrm{T}$ cells from NSCLC TIL and healthy donor (HD) peripheral blood mononuclear cells (PBMC) only rarely expressed the integrin (Supplementary Fig. 2c and d). To select a NSCLC cell line that expresses $\alpha_{V}$ for further studies, we tested a panel of 13 cell lines by FACS. While $\alpha_{V}$ was expressed in nine cell lines, the $\beta_{6}$ and $\beta_{8}$ subunits were much less frequently expressed (Supplementary Table 4). Among these cell lines, we retained the IGR-B2 because it expressed the three subunits that likely form $\alpha_{V} \beta_{6}$ and $\alpha_{V} \beta_{8}$ heterodimers (Fig. 2c). In addition, qRT-PCR showed that IGR-B2 did not express ITGB1 and ITGB5 genes, which were over-expressed in five and four cell lines as compared to 16HBE human bronchial epithelial cells (Supplementary Table 5), but over-expressed, together with seven other cell lines, ITGB3, suggesting that $\alpha_{\mathrm{V}}$ may also pair with $\beta_{3}$ in these cells. Thus, the role of other $\alpha_{V}$ integrins in this human tumour model cannot be ruled out.

We then assessed the capacity of $\alpha_{V}$ integrins on IGR-B2 to activate LAP-TGF- $\beta$. Since IGR-B2 does not produce high levels of TGF- $\beta$, although TGFB1 mRNA was detected by qRT-PCR (Supplementary Table 5), we first transfected the cell line with a human LAP-TGF- $\beta$-encoding plasmid and selected a clone (IGR$\mathrm{B} 2 \mathrm{~T}$ ) producing strong levels of TGF- $\beta$ (Fig. 2d). Using the CRISPR-Cas9 system, we also generated from IGR-B2T a cell clone knockout $(\mathrm{KO})$ for the $\alpha_{\mathrm{V}}$ subunit (IGR-B2T-KO) to suppress all $\alpha_{\mathrm{V}}$ integrins (Fig. 2e). Notably, deletion of the ITGAV gene in IGR-B2T-KO cells resulted in dramatic morphology changes with loss of the adhesive capacity and formation of spheroids (Fig. 2f). Nevertheless, these changes did not affect IGR-B2T-KO susceptibility to autologous CTL clone-mediated killing, excluding alteration in target cell recognition (Supplementary Fig. 2e). We then conducted experiments to determine the capacity of $\alpha_{V}$ integrins on IGR-B2T cells to activate LAPTGF- $\beta$. Results showed that while IGR-B2T and IGR-B2T-KO produced equal levels of LAP-TGF- $\beta$, IGR-B2T-KO cells produced lower quantities of active TGF- $\beta$ as measured by luciferase activity (Fig. 2d). However, inhibition of TGF- $\beta$ activation in IGR-B2T-KO was incomplete, suggesting that additional mechanisms may activate the cytokine.

Next, we asked whether tumour-derived active TGF- $\beta$ participates in the formation of $\mathrm{T}_{\mathrm{RM}}$ cells such as by inducing

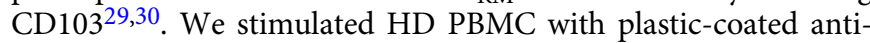
$\mathrm{CD} 3 \mathrm{mAb}$ in the presence of conditioned medium (CM) from IGR-B2T or IGR-B2T-KO cells, and evaluated CD103 expression on $\mathrm{CD}^{+} \mathrm{T}$ cells. Activation of T lymphocytes with anti-CD3 plus CM from IGR-B2T resulted in induction of CD103 on up to $70 \%$ of $\mathrm{CD}^{+} \mathrm{T}$ cells (Fig. 3a and Supplementary Fig. 3). In contrast, stimulation of PBMC with anti-CD3 plus CM from IGR-B2T-KO triggered CD103 expression on only up to $22 \%$ of $\mathrm{CD}^{+} \mathrm{T}$ lymphocytes. Stimulation with anti-CD3 alone or CM alone did not induce CD103 expression, and a combination of anti-CD3 plus recombinant (r)TGF- $\beta$, used as a positive control, induced expression of the integrin in a dose-dependent manner (Fig. 3b). Moreover, the supply of rTGF- $\beta$ to CM from IGR-B2T-KO resulted in increased expression of CD103 (Fig. 3b). In contrast, the addition of anti-TGF- $\beta$ neutralizing $\mathrm{mAb}$ to $\mathrm{CM}$ from IGRB2T inhibited CD103 induction (Fig. 3c). These data indicate that $\alpha_{V}$ integrins on tumour cells activate TGF- $\beta$ and thereby regulate CD103 expression on activated $\mathrm{CD}^{+} \mathrm{T}$ cells.

Tumour $\alpha_{V}$ shapes the TME by activating TGF- $\beta$. The above data suggest that by activating TGF- $\beta$, tumour $\alpha_{\mathrm{V}}$ determines the nature of $\mathrm{CD}^{+} \mathrm{T}$ cell infiltrate and therefore anti-tumour $\mathrm{T}$ cell immunity and response to immunotherapy. To test this hypothesis, we developed an in vivo model of C57BL/6 mice engrafted with B16F10 melanoma cells transfected with the CD103 ligand E-cadherin (B16F10E) to mimic epithelial tumours. We selected B16F10 because it expressed $\alpha_{V}$ and $\beta_{8}$ subunits, produced constitutively LAP-TGF- $\beta$ (Supplementary Fig. $4 \mathrm{a}-\mathrm{c}$ ) and is known to respond to $\mathrm{ICB}^{31}$. Notably, B16F10E does not express $\beta_{1}, \beta_{3}, \beta_{5}$, and $\beta_{6}$ subunits tested by qRT-PCR and/or FACS (Supplementary Fig. 4a). Using the CRISPR-Cas9 system, we generated a cell clone deficient for $\alpha_{V}(B 16 F 10 E-K O)$ which displayed similar expression levels of E-cadherin as the parental clone (Supplementary Fig. 4d). As for human IGR-B2-KO, we observed dramatic morphological changes in B16F10E-KO cells compared to $\mathrm{B} 16 \mathrm{~F} 10 \mathrm{E}$, with loss of plastic adhesive capacity (Supplementary Fig. 4b). Moreover, luciferase activity assay showed that B16F10E-KO produced lower levels of active TGF- $\beta$ than B16F10E even though both tumour cell clones secreted similar levels of the cytokine latent form (Supplementary Fig. 4c). 
a
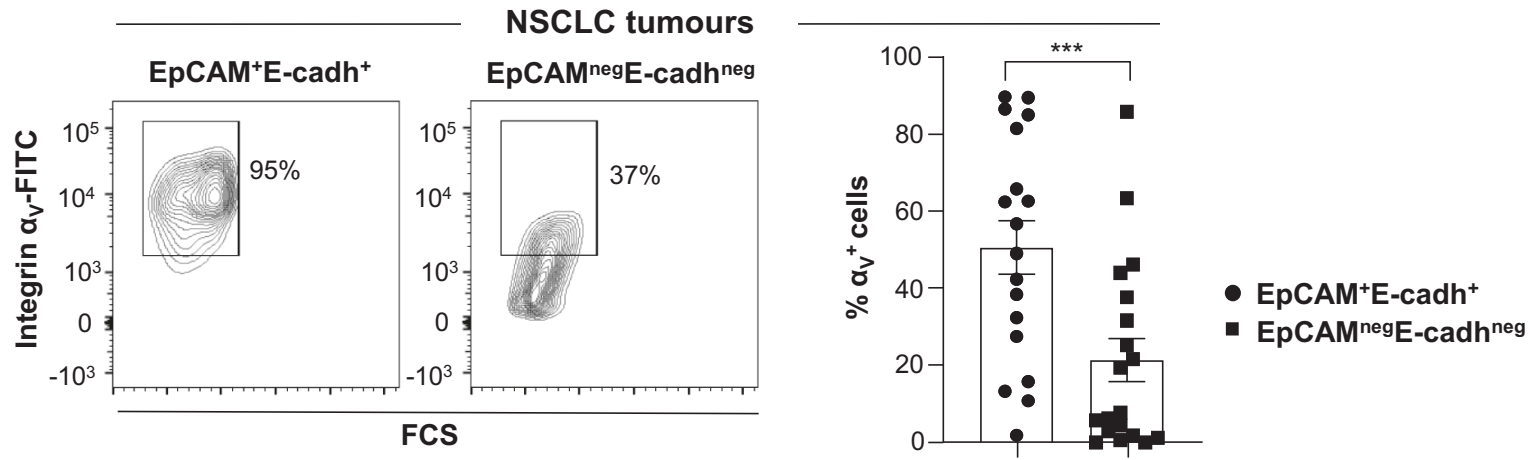

b
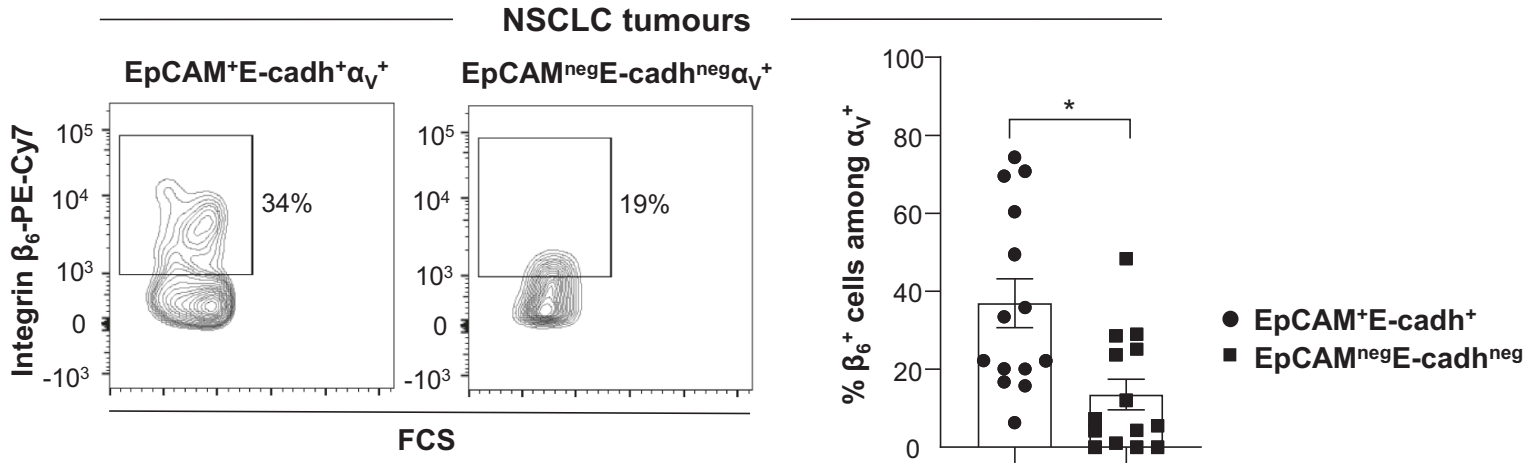

C

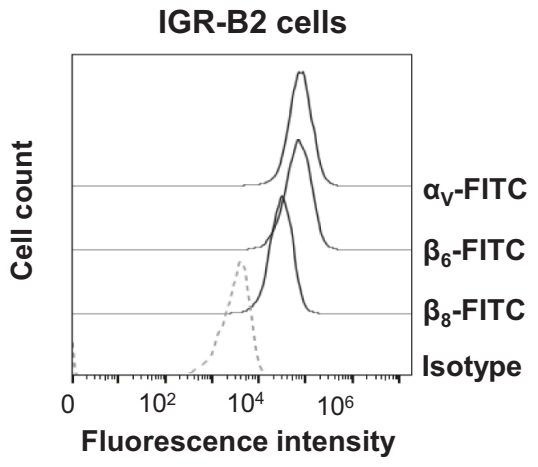

e

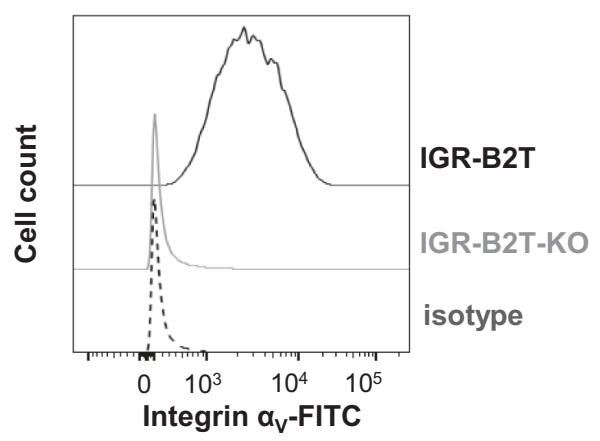

d

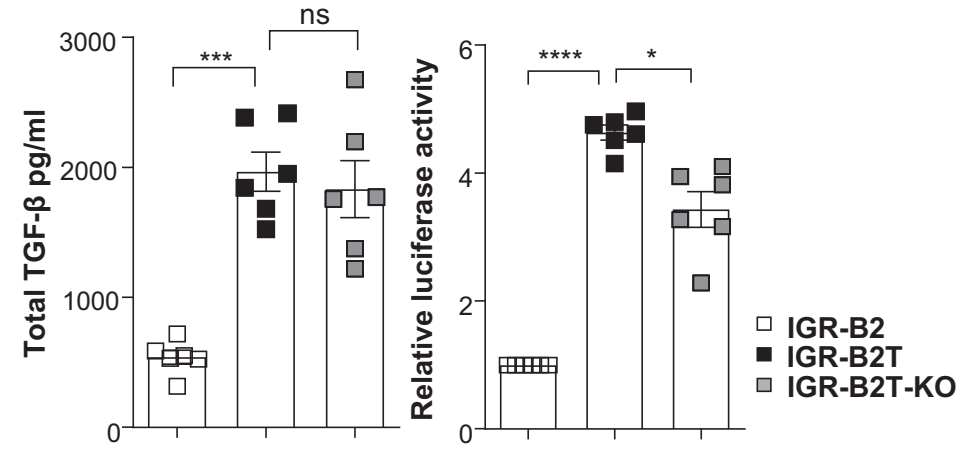

f
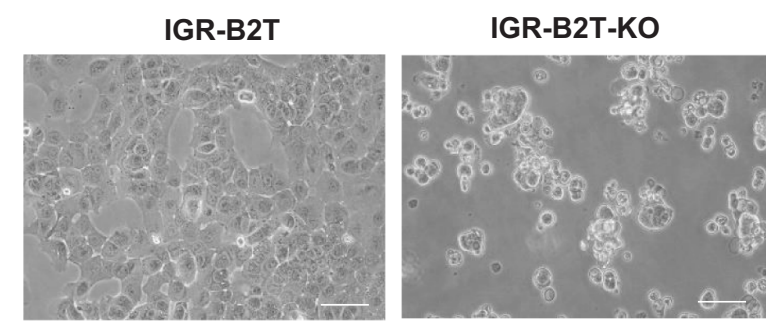

Activation of LAP-TGF- $\beta$ was associated with the interaction of $\alpha_{V}$ integrin with LAP-TGF- $\beta$ in B16F10E, but not in B16F10E$\mathrm{KO}$ negative control, as examined by proximity ligation assay (PLA) and confocal microscopy (Supplementary Fig. 4e). In addition, $\mathrm{CM}$ from $\mathrm{B} 16 \mathrm{~F} 10 \mathrm{E}$, and to a much lesser extent from $\mathrm{B} 16 \mathrm{~F} 10 \mathrm{E}-\mathrm{KO}$, induced expression of CD103 on T cell-receptor (TCR)-engaged $\mathrm{CD}^{+} \mathrm{T}$ cells from HD PBMC (Supplementary Fig. 4f). Like for IGR-B2T-KO, inhibition of TGF- $\beta$ activation in B16F10E-KO cells was partial, supporting the hypothesis that additional mechanisms, such as metalloproteases (MMP) 23,24 , are involved in the maturation of LAP-TGF- $\beta$. Consistently, B16F10E expressed MMP14, previously shown to release latent TGF- $\beta$ from cell-extracellular matrix ${ }^{23}$ (Supplementary Fig. 4g). Moreover, stimulation of HD PBMC with anti-CD3 plus CM from B16F10E treated with the MMP inhibitor GM6001 resulted in decreased expression of CD103 on $\mathrm{CD}^{+} \mathrm{T}$ cells as compared to CM from untreated cells (Supplementary Fig. 4h).

To examine the impact of $\alpha_{V}$ integrins on anti-tumour $\mathrm{T}$ cell response in vivo, we engrafted $\mathrm{B} 16 \mathrm{~F} 10 \mathrm{E}$ and $\mathrm{B} 16 \mathrm{~F} 10 \mathrm{E}-\mathrm{KO}$ cells in C57BL/6 mice and followed tumour development. We first 
Fig. 2 Human NSCLC tumour cells express $\boldsymbol{\alpha}_{\mathbf{v}}$ integrin, which activates autocrine TGF- $\boldsymbol{\beta}$. a Representative flow cytometry plots (bi-exponential scale) of $\alpha_{V}$ expression in $\mathrm{EpCAM}^{+} \mathrm{E}$-cadherin ${ }^{+}$and $\mathrm{EpCAM}^{\text {neg }} \mathrm{E}$-cadherin ${ }^{\text {neg }}$ cells from a lung tumour. Right, percentage of $\alpha_{V}$ expression in $\mathrm{EpCAM}^{+} \mathrm{E}$-cadherin $^{+}$ and EpCAM ${ }^{\text {negE-cadherin }}{ }^{\text {neg }}$ cells $\left(n=18,{ }^{* \star *} p=0.0002\right)$. b Representative flow cytometry plots of $\beta_{6}$ subunit expression in EpCAM ${ }^{+E}$-cadherin ${ }^{+} \alpha_{V}{ }^{+}$and EpCAM ${ }^{\text {negE-cadherin }}{ }^{\text {neg }} \alpha_{V}{ }^{+}$cells from a tumour sample. Right, expression of $\beta_{6}$ integrin in EpCAM+E-cadherin ${ }^{+} \alpha_{V}{ }^{+}$and EpCAMnegE-cadherin ${ }^{\text {neg }} \alpha_{V}{ }^{+}$ cells $(n=16),{ }^{\star} p=0.013$. c Surface expression of $\alpha_{v}, \beta_{6}$, and $\beta_{8}$ subunits in the IGR-B2 cell line. $\mathbf{d}$ Concentration of total TGF- $\beta$ in CM from IGR-B2, IGRB2T, and IGR-B2T-KO cells measured by ELISA ( $\left.{ }^{\star \star *} p=0.0004\right)$. Results are presented as mean \pm SEM of six independent experiments. Right, relative luciferase activity in the Mu.1LV cell line transfected with (CAGA)9-Lux reporter plasmid and treated with CM from IGR-B2, IGR-B2T, and IGR-B2T-KO cells, normalized to luciferase activity in Mu.1LV cell treated with CM from IGR-B2. Results are presented as mean \pm SEM of six independent experiments $\left({ }^{\star} p=0.011,{ }^{\star \star \star *} p<0.0001\right)$. e Expression of $\alpha_{V}$ integrin on IGR-B2T and IGR-B2T-KO cells. An isotype control was included. $\mathbf{f}$ Representative photos of the morphology of IGR-B2T and IGR-B2T-KO cells by phase-contrast light microscope from one experiment out of five. Objective: $20 \times$. Each symbol represents the individual cell type from tumour samples $(\mathbf{a}, \mathbf{b})$; horizontal lines correspond to mean $\pm \operatorname{SEM}(\mathbf{a}, \mathbf{b}, \mathbf{d})$. Data were calculated with paired Student $t$-tests (a, b) and one-way ANOVA with Tukey's correction (d). ns: non-significant. Source data are provided as a Source Data file.

verified that both tumour cell clones proliferated equally in vitro, using the CFSE assay, and in vivo, after engraftment into immune-deficient nude mice (Supplementary Fig. 5a, b). Implanting B16F10E and B16F10E-KO into immune-competent C57BL/6 mice resulted in similar tumour growth kinetics and tumour weights (Fig. 4a). In these series of experiments, we checked that B16F10E tumours produced higher levels of active TGF- $\beta$ than B16F10E-KO ex vivo (Fig. 4b). Notably, CD8 ${ }^{+}$and CD4 ${ }^{+}$TIL from both B16F10E and B16F10E-KO expressed the $\alpha_{V}$ integrin, which may participate in TGF- $\beta$ activation (Supplementary Figs. 5c and 6a). More importantly, B16F10E$\mathrm{KO}$ tumours were more strongly infiltrated with $\mathrm{CD}^{+}$and $\mathrm{CD}^{+} \mathrm{T}$ cells than B16F10E (Fig. 4c). Moreover, CD8 ${ }^{+} \mathrm{T}$ cells from $\mathrm{B} 16 \mathrm{~F} 10 \mathrm{E}-\mathrm{KO}$ were more enriched with $\mathrm{CD} 44^{+} \mathrm{CD} 62 \mathrm{~L}^{\text {neg }}$ effector cells than those from B16F10E (Fig. 4d). In contrast, both tumours were equally infiltrated with $\mathrm{CD} 4^{+} \mathrm{T}$ cells, which included similar percentages of $\mathrm{CD} 44^{+} \mathrm{CD} 62 \mathrm{~L}^{\text {neg }}$ cells (Supplementary Fig. 6b). B16F10E and B16F10E-KO tumours were also equally infiltrated with $\mathrm{CD}_{103}{ }^{+} \mathrm{CD} 45^{+} \mathrm{CD} 3^{-} \mathrm{MHC}-\mathrm{II}^{+} \mathrm{CD} 11 \mathrm{c}^{+}$ DC (Supplementary Fig. 6c). Remarkably, $\mathrm{CD}^{+} \mathrm{T}$ cells from B16F10E-KO were more enriched with $\mathrm{KLRG}^{+}$effectors and activated $\mathrm{CD}_{69}{ }^{+}$cells, and less enriched with $\mathrm{CD}_{103}{ }^{+}$cells than B16F10E (Fig. 4e), which correlated with a decreased production of active TGF- $\beta$ by the former tumours. Consistent with this, transcription factors $S m a d 2 / 3$ were less frequently phosphorylated in $\mathrm{CD}^{+} \mathrm{T}$ lymphocytes from B16F10E-KO than B16F10E tumours (Supplementary Fig. 6d). CD8 ${ }^{+} \mathrm{T}$ cells from B16F10E$\mathrm{KO}$ were also more highly enriched with activated $\mathrm{PD}-1^{+}$and proliferative $\mathrm{Ki}-67^{+}$cells than $\mathrm{B} 16 \mathrm{~F} 10 \mathrm{E}$ emphasizing a higher activation state (Fig. 4f, g). These results indicate that knockout of tumour $\alpha_{\mathrm{V}}$ results in increased recruitment and activation of $\mathrm{CD}^{+} \mathrm{T}$ cells, most likely linked to modulation of TGF- $\beta$ maturation.

Knockout of $\alpha_{\mathrm{V}}$ improves CD8 T cell immunity and response to anti-PD-1. The above-described human studies showed that tumour $\alpha_{V}$ expression levels influence the outcome of anti-PD-1treated NSCLC patients via a mechanism dependent on increased density of $\mathrm{CD}^{+}$TIL. To evaluate the impact of tumour $\alpha_{\mathrm{V}}$ expression on response to ICB in vivo, we engrafted C57BL/6 mice with B16F10E and B16F10E-KO cells, treated them with anti-PD-1, and monitored tumour progression. Results indicated that intraperitoneal (i.p.) administration of neutralizing anti-PD$1 \mathrm{mAb}$ greatly improved control of B16F10E-KO tumour growth, but not B16F10E growth (Fig. 5a). In contrast, isotype controltreated mice displayed similar tumour progression kinetics and tumour weight. B16F10E-KO growth control in anti-PD-1treated mice was associated with an increase in tumour infiltration by $\mathrm{CD}^{+} \mathrm{T}$ cells compared to isotype control-treated mice (Fig. 5b), and this benefit was abolished when mice received antiCD8 blocking mAb (Fig. 5c).
Next, we examined the consequence of tumour $a_{\mathrm{V}}$-knockout combined with PD-1 blockade on the quality and functionality of $\mathrm{CD}^{+}$TIL. Multi-parametric immunofluorescence analyses indicated that $\mathrm{CD}^{+}{ }^{+}$TIL from anti-PD-1-treated B16F10E-KO tumours was more enriched with terminally differentiated $\mathrm{KLRG}^{+}$effector $\mathrm{T}$ cells than those from isotype-treated B16F10E-KO and anti-PD-1-treated B16F10E (Fig. 5d). Notably, $\mathrm{CD}^{+}{ }^{+} \mathrm{TIL}$ from anti-PD-1-treated B16F10E-KO was only marginally less enriched with $\mathrm{CD}_{103}{ }^{+} \mathrm{T}$ cells than those from isotype-treated $\mathrm{B} 16 \mathrm{~F} 10 \mathrm{E}-\mathrm{KO}$ and anti-PD-1-treated $\mathrm{B} 16 \mathrm{~F} 10 \mathrm{E}$ tumours (Supplementary Fig. 7a). In contrast, much lower percentages of $\mathrm{CD}_{103}{ }^{+}$cells among $\mathrm{FoxP} 3^{+} \mathrm{CD} 4^{+}$Treg were observed in B16F10E-KO tumours than in B16F10E (Supplementary Fig. 7b). Moreover, CD8 ${ }^{+} \mathrm{T}$ lymphocytes from anti-PD1-treated B16F10E-KO, but not from B16F10E, displayed increased percentages of $\mathrm{Ki}-67^{+}$cells as compared to isotypetreated $\mathrm{B} 16 \mathrm{~F} 10 \mathrm{E}-\mathrm{KO}$ suggesting that $\mathrm{PD}-1$ blockade promoted $\mathrm{CD}^{+} \mathrm{T}$ cell expansion in the former tumours associated with decreased TGF- $\beta$ activation (Fig. 5e). In contrast, $\mathrm{CD}^{+} 9^{+} \mathrm{CD} 103^{+}$ $\mathrm{T}$ cells from untreated and anti-PD-1-treated B16F10E and B16F10E-KO tumours displayed similar percentages of $\mathrm{Ki}-67^{+}$ lymphocytes. More importantly, CD8 ${ }^{+}$TIL from B16F10E-KO was much more strongly enriched with granzyme $\mathrm{B}^{+} \mathrm{T}$ cells than B16F10E untreated or treated with anti-PD-1, with no further enrichment after PD-1 blockade in the former tumours (Fig. 5f). Anti-PD-1-treated-B16F10E-KO-derived $\mathrm{CD}^{+}{ }^{+} \mathrm{T}$ cells were also more enriched with $\mathrm{CD} 69^{+} \mathrm{CD} 103^{+}$TIL than $\mathrm{CD} 8^{+} \mathrm{T}$ cells from isotype-treated $\mathrm{B} 16 \mathrm{~F} 10 \mathrm{E}-\mathrm{KO}$ and $\mathrm{B} 16 \mathrm{~F} 10 \mathrm{E}$ treated with anti-PD1. Moreover, $\mathrm{CD} 69^{+} \mathrm{CD} 103^{+} \mathrm{CD} 8{ }^{+} \mathrm{T}$ cells from anti-PD-1treated $\mathrm{B} 16 \mathrm{~F} 10 \mathrm{E}-\mathrm{KO}$ tumours expressed more frequently granzyme B than isotype-treated B16F10E-KO (Fig. 5f). Accordingly, $\mathrm{CD}^{+}$TIL from anti-PD-1-treated B16F10E-KO was able to kill the cognate tumour target slightly more than $\mathrm{CD}^{+}$TIL from isotype-treated B16F10E-KO (Fig. 5g). Cytotoxicity correlated with upregulation of MHC-I and PD-L1 molecules on anti-PD-1treated B16F10E-KO tumour cells as compared to isotype-treated B16F10E-KO (Supplementary Fig. 7c), which correlated with high production of IFN $\gamma$ by CD8 ${ }^{+}$TIL (Supplementary Fig. $7 d$ ). However, a comparison between anti-PD-1-treated B16F10E and anti-PD-1-treated B16F10E-KO for the expression of MHC-I and PD-L1 did not reveal significant differences suggesting that the observed CTL-mediated activities in $\alpha_{\mathrm{V}}-\mathrm{KO}$ tumours were not associated with optimized antigen presentation by target cells nor with decreased PD-L1 expression. These results suggest that decreased tumour $\alpha_{\mathrm{V}}$ expression and concomitant inhibition of autocrine TGF- $\beta$ maturation result in recruitment and activation of tumour-reactive $\mathrm{CD} 8^{+} \mathrm{T}$ cells.

$\mathrm{CD8}^{+} \mathrm{T}_{\mathrm{RM}}$ cells are involved in anti-PD-1 response of $\boldsymbol{\alpha}_{\mathrm{V}}-\mathrm{KO}$ tumours. The above studies suggest that $\mathrm{CD} 103^{+} \mathrm{CD} 8^{+} \mathrm{T}$ cells are implicated in response to anti-PD-1 and that tumour 
a

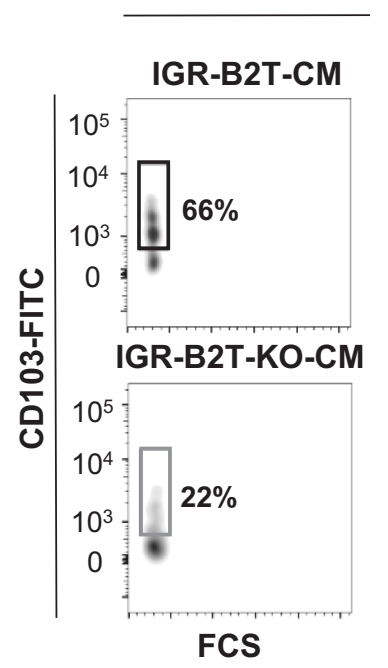

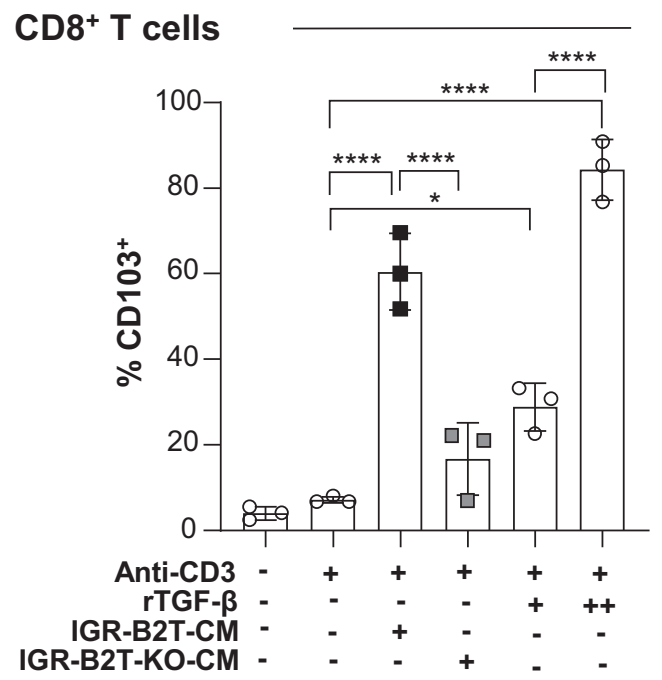

IGR-B2T-CM

IGR-B2T-KO-CM

○ CM-free

b

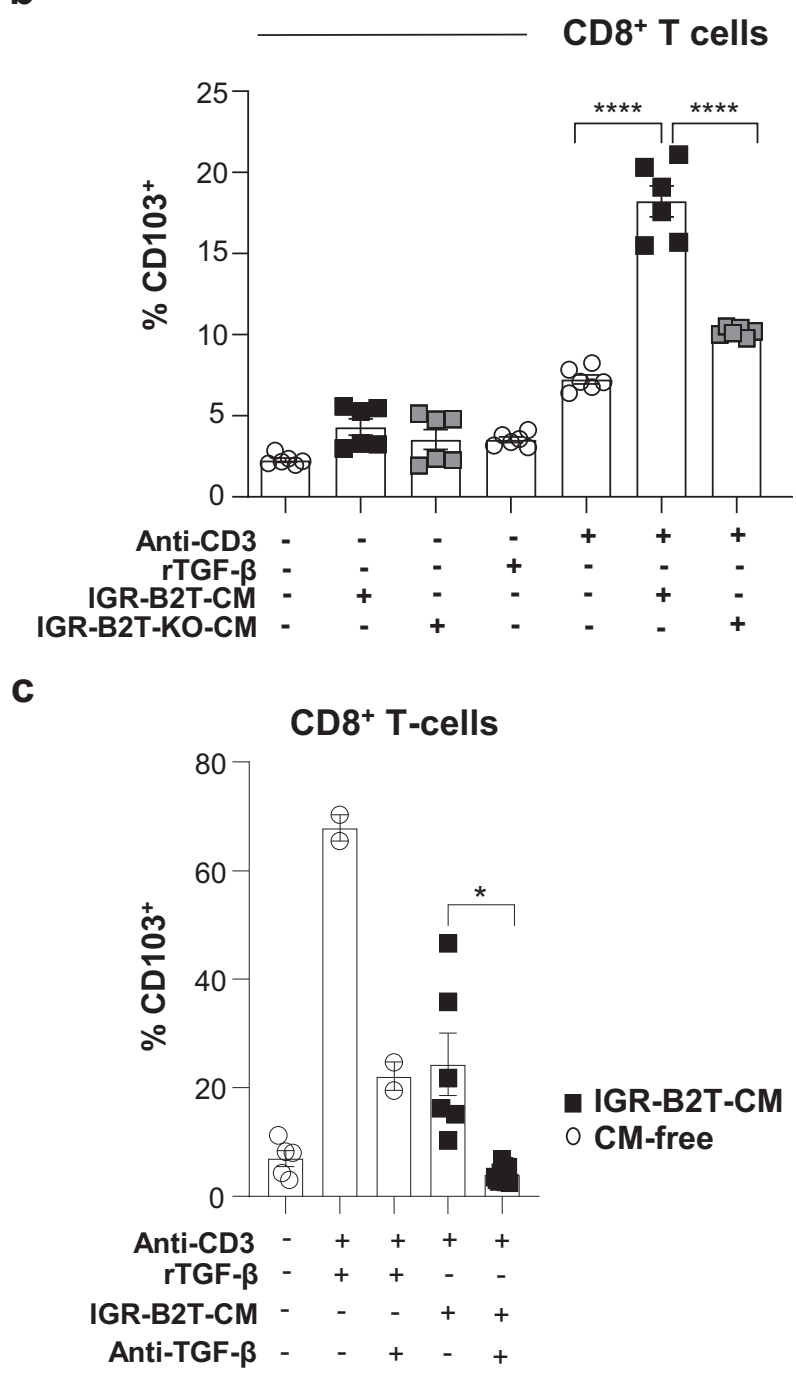

- IGR-B2T-CM $\square$ IGR-B2T-KO-CM O CM-free
$a_{\mathrm{V}}$-knockout does not eradicate their formation at the tumour site. To test this hypothesis, mice were engrafted with B16F10E$\mathrm{KO}$, treated with anti-PD-1, then received anti-CD103 blocking $\mathrm{mAb}$ or isotype control, and followed for tumour development. Results indicated that the beneficial effect of PD-1 blockade was inhibited when mice received intra-tumoural injection of
anti-CD103 (Fig. 6a). This inhibition was associated with a decrease in target cell killing by $\mathrm{CD} 8^{+}$TIL from anti-PD-1 plus anti-CD103-treated $\mathrm{B} 16 \mathrm{~F} 10 \mathrm{E}-\mathrm{KO}$ as compared to $\mathrm{CD}^{+} \mathrm{TIL}$ from anti-PD-1 plus isotype-treated tumours (Fig. 6b). Notably, anti-CD103 alone had no effect on tumour growth and weight of B16F10E-KO (Fig. 6c) and B16F10E (Supplementary Fig. 7e). 
Fig. 3 CM of IGR-B2T cells promotes CD103 expression in activated human CD8 ${ }^{+} \mathbf{T}$ cells. a Representative flow cytometry plots (bi-exponential scale) of the expression of CD103 in CD8 ${ }^{+}$T cells from HD PBMC stimulated for three days with plastic-coated anti-CD3 mAb in the presence of CM from IGRB2T or IGR-B2T-KO cells. Right, percentages of $\mathrm{CD}_{103}{ }^{+}$cells among CD8 ${ }^{+}$T cells of non-stimulated and stimulated PBMC $(n=3)$. Recombinant $(r)$ TGF- $\beta$ at $1 \mathrm{ng} / \mathrm{ml}(+)$ or $5 \mathrm{ng} / \mathrm{ml}(++)$ was used as a positive control $\left({ }^{\star} p=0.011,{ }^{\star \star \star *} p<0.0001\right)$. b Percentages of CD103 ${ }^{+}$cells among CD8 ${ }^{+} \mathrm{T}$ lymphocytes from HD PBMC unstimulated or stimulated for three days with anti-CD3 alone, rTGF- $\beta$ alone, CM alone, and a combination of anti-CD3 plus CM from IGRB2T or IGR-B2T-KO cells $(n=6)$. Right, rescue experiments. Percentages of CD103+ lymphocytes among CD8 ${ }^{+}$T cells stimulated with a combination of anti-CD3 plus CM from IGR-B2T-KO cells, CM from IGR-B2T-KO plus low dose $(1 \mathrm{ng} / \mathrm{ml})$ of $r$ TGF- $\beta$, and anti-CD3 plus rTGF- $\beta$, included as a control $\left(n=3,{ }^{\star} p=0.048,{ }^{\star \star \star \star} p<0.0001\right)$. c Inhibition of CD103 induction with anti-TGF- $\beta$ blocking mAb. Percentages of CD103 ${ }^{+}$lymphocytes among CD8 ${ }^{+}$ T cells stimulated with CM from IGR-B2T plus anti-CD3 in the absence and presence of anti-TGF- $\beta$ mAb $\left(n=6,{ }^{*} p=0.022\right)$. A combination of anti-CD3 and rTGF- $\beta$ alone and in presence of neutralizing anti-TGF- $\beta$ was included as a control. Each symbol represents an individual cell type. Horizontal lines correspond to mean \pm SEM. Data were calculated with one-way ANOVA with Tukey's correction (a, $\mathbf{b})$ and paired Student $t$-test (c). Source data are provided as a Source Data file.

Anti-CD103 alone had also no effect on the number of TIL and $\mathrm{CD}^{+} \mathrm{T}$ cells in B16F10E-KO (Fig. 6d) and B16F10E (Supplementary Fig. $7 \mathrm{f}$ ) and on the percentage of conventional (c)DC and $\mathrm{CD}_{103}{ }^{+} \mathrm{cDC}$ in both tumours (Supplementary Fig. 7g, h). These data suggest that a $\mathrm{CD} 103^{+} \mathrm{CD} 8^{+}$TIL subset is involved in tumour growth control and that this subset is differentiated in the TME independently of tumour $\alpha_{\mathrm{V}}$-mediated TGF- $\beta$ activation.

To test whether TGF- $\beta$ is mandatory for the differentiation of $\mathrm{CD} 103^{+} \mathrm{CD}^{+} \mathrm{T}$ cells in the tumour and response to $\mathrm{PD}-1$ blockade, B16F10E-KO-engrafted mice were treated with anti-PD-1, received intra-tumoural injection of neutralizing anti-TGF- $\beta$ mAb or isotype control, and monitored for tumour progression. Results showed that a combination of anti-PD-1 plus anti-TGF- $\beta$ had only a marginal effect on tumour growth (Fig. 6e) and infiltration by TIL and $\mathrm{CD}^{+} \mathrm{T}$ cells, even though a decrease in the percentages of $\mathrm{CD} 103^{+} \mathrm{CD}^{+} 9^{+} \mathrm{CD}^{+} \mathrm{T}$ cells was observed (Fig. 6f). Notably, antiTGF- $\beta$ alone had also no effect on B16F10E-KO tumour weight as compared to isotype control, and an increase in tumour growth was even observed (Fig. 6c). No effect was also observed on B16F10E tumour growth and weight (Supplementary Fig. 7e), and on the number of TIL and CD8 ${ }^{+} \mathrm{T}$ cells in B16F10E-KO (Fig. 6d), the number of TIL in B16F10E (Supplementary Fig. 7f), and on the percentage of $\mathrm{cDC}$ and $\mathrm{CD}_{103}{ }^{+} \mathrm{cDC}$ infiltrating both tumours (Supplementary Fig. 7g, h). These data support the observation that $\mathrm{CD}^{+} \mathrm{T}_{\mathrm{RM}}$ cells play an important role in response to anti-PD-1 and that TGF- $\beta$ is involved in their formation in a cancer-cell- $\alpha_{\mathrm{V}^{-}}$ integrin-independent manner.

\section{Discussion}

In this report, we show that $\alpha_{\mathrm{V}}$ integrin is frequently expressed by NSCLC tumours. This integrin is produced by multiple cell types, ranging from immune cells to cancer cells, and it is known to be a key activator of LAP-TGF- $\beta^{32}$. A critical role for $\alpha_{V}$ integrin family members, including $\alpha_{V} \beta_{6}$ and $\alpha_{V} \beta_{8}$, has been highlighted in regulating tissue and immune homeostasis by activating TGF$\beta$. In this respect, it has been reported that fibroblast $\alpha_{V}$ regulates inflammation and fibrosis in the lung by a mechanism involving TGF- $\beta$ activation ${ }^{33}$. Integrin $\alpha_{\mathrm{V}}$-mediated activation of TGF- $\beta$ also promotes tumour progression through multiple pathways including epithelial-to-mesenchymal transition, an increase of angiogenesis and invasion, formation of cancer-associated fibroblasts, and suppression of $\mathrm{T}$ cell-mediated immune surveillance 34,35 . Consistently, we show here that tumour $\alpha_{\mathrm{V}}$ interacts and activates autocrine TGF- $\beta$ and that its knockout inhibits activation of the cytokine and reshapes the phenotypic and functional proprieties of $\mathrm{CD}^{+}$TIL. This inhibition is incomplete emphasizing that additional mechanisms, such as MMP14 on cancer cells and $\alpha_{V}$ integrin on infiltrating immune cells, including $\mathrm{CD}^{+}$and CD4 ${ }^{+}$TIL, and $\mathrm{DC}^{28,36}$, can activate latent TGF- $\beta$ within the TME.
Targeting tumour $\alpha_{V}$ has been proposed as a strategy for cancer treatment. In this regard, blocking $\alpha_{\mathrm{V}} \beta_{8}$ and subsequent TGF- $\beta$ activation has been shown to inhibit tumour growth by a mechanism independent of PD-1/PD-L1 ${ }^{27}$. Therefore, multiple potential therapeutic agents, such as $\alpha_{\mathrm{V}}$-RGD inhibitors and tumour-homing peptide (iRGD), have been developed for treating neoplasms, including lung cancer ${ }^{32,37,38}$. Targeting the ITGAV gene has also been used as a therapeutic approach for metastatic cancer ${ }^{39}$. Notably, antagonists of $\alpha_{\mathrm{V}}$ observed promising preclinical results with anti-angiogenic and anti-metastatic effects $^{40}$. However, most of the clinical trials with inhibitors targeting $\alpha_{\mathrm{V}}$ integrin failed to demonstrate therapeutic benefits ${ }^{32}$. Along the same lines, our data indicate that decreased expression of $\alpha_{V}$ in lung tumours had no effect on survival in treatmentnaïve NSCLC patients. In addition, although tumour $\alpha_{\mathrm{V}}$-knockout greatly increased tumour infiltration by CD8 T lymphocytes in our mouse model, it failed to delay tumour progression. Indeed, our in vivo studies showed similar growth kinetics of $\alpha_{\mathrm{V}^{-}}$ proficient and-deficient tumours even though the latter were much more strongly infiltrated by proliferative $\mathrm{PD}-1^{+} \mathrm{CD} 8{ }^{+}$ effector T cells. Thus, it is clear that targeting tumour $\alpha_{V}$ as single therapeutic agent is not sufficient in the clinical setting to reliably eradicate cancer. TGF- $\beta$ inhibitors as single therapeutic agents also observed limited clinical success, likely due to restricted targeting of TGF- $\beta$-responsive cells and inadequate effects on cancer cell proliferation ${ }^{41}$. Consistently, targeting TGF- $\beta$ with neutralizing $\mathrm{mAb}$ had no effect on $\mathrm{B} 16 \mathrm{~F} 10 \mathrm{E}$ tumour growth. Moreover, the development of cancer therapies targeting TGF- $\beta$ signalling has been hindered by dose-limiting toxicities ${ }^{42}$. Thus, targeting tumour $a_{V}$ in combination with ICB appears a promising strategy to selectively target non-immune cells and ensure a superior safety profile compared to TGF- $\beta$ inhibitors.

Tumour $\alpha_{V}$ integrin is considered as a serious cause of resistance to ICB by activating TGF- $\beta$ and thereby excluding CD8 ${ }^{+}$ $\mathrm{T}$ cells from the TME. Therefore, manipulating $\alpha_{\mathrm{V}}$ seems a promising approach to improve the clinical success of ICB. In this context, we show that decreased expression of tumour $a_{V}$ correlates with improved outcome in NSCLC patients treated with anti-PD-(L)1. Our data indicate that $a_{V}$ low tumour-bearing patients displayed improved PFS compared to $\alpha_{V}$ high tumourbearing patients associated with an increase in tumour infiltration by $\mathrm{CD} 103^{+} \mathrm{CD}^{+}$lymphocytes. Moreover, our in vivo mouse model revealed that tumour $\alpha_{V}$ knockout combined with antiPD-1 resulted in delayed tumour progression likely associated with decreased TGF- $\beta$ activation and concomitant $\mathrm{T}$ cell recruitment. Consistently, blockade of $\alpha_{V} \beta_{8}$ and PD-1 synergistically promoted better anti-tumour response and more beneficial effects $^{27}$. The present study further shows that beneficial effects are likely associated with improved CD8 T cell immunity and increased tumour infiltration by tumour-specific $\mathrm{CD} 103^{+} \mathrm{CD} 69^{+}$ $\mathrm{T}_{\mathrm{RM}}$ cells. Indeed, tumour growth control was dependent on 


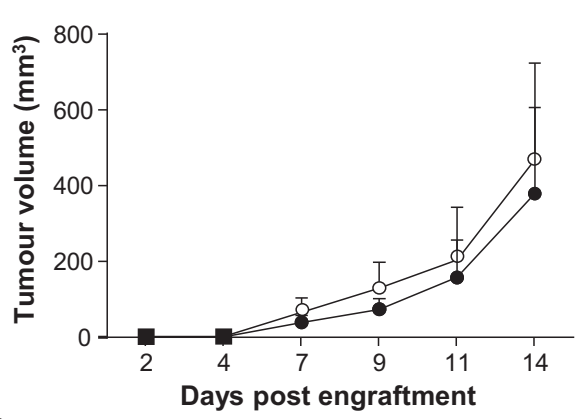

C

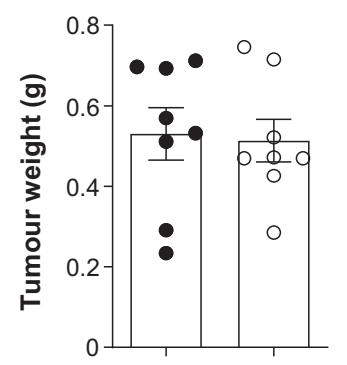

d b

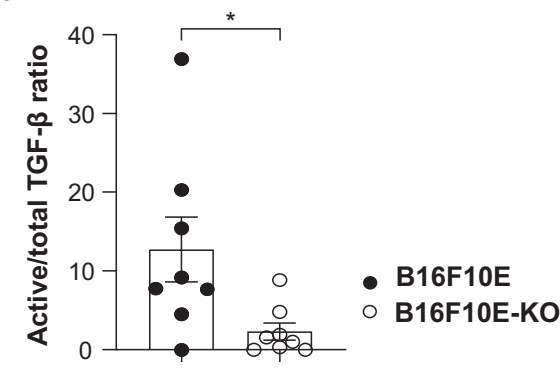

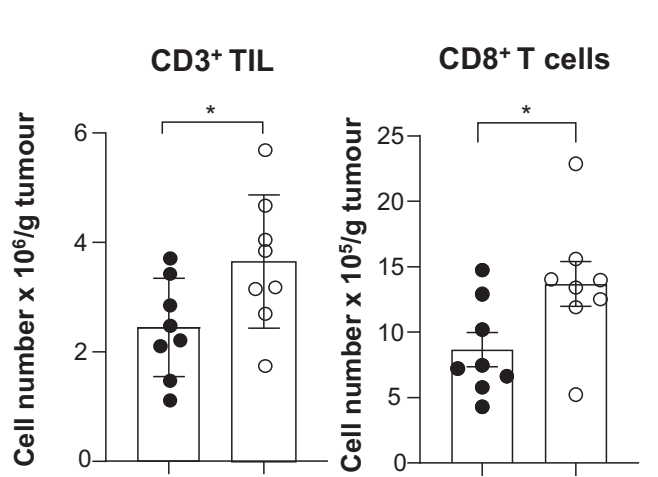

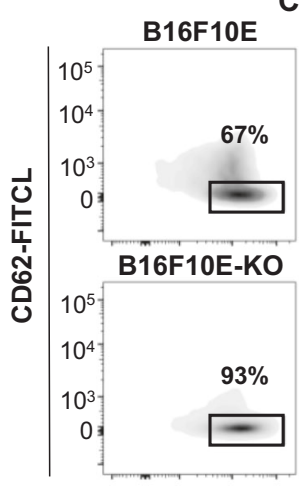

CD8 $^{+} \mathrm{T}$ cells

CD44

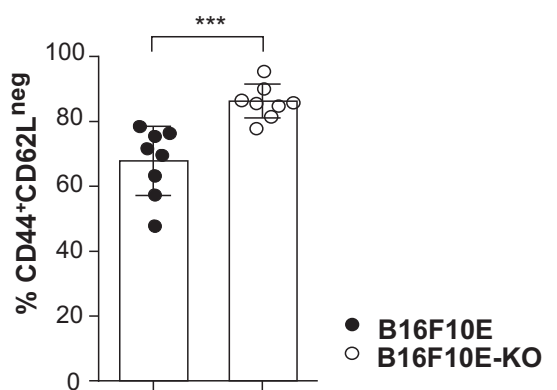

e

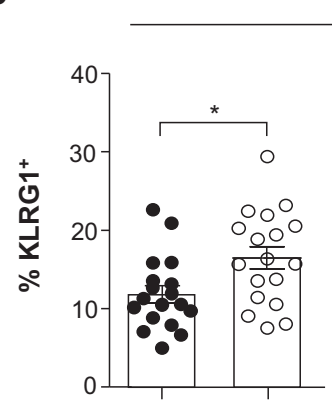

CD8 ${ }^{+} \mathrm{T}$ cells

f

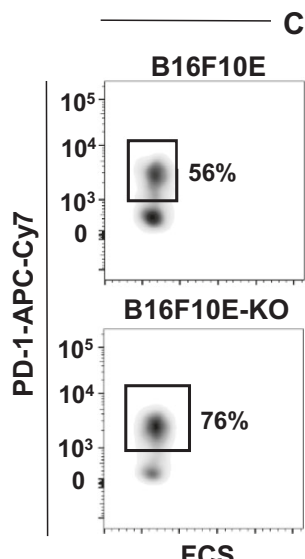

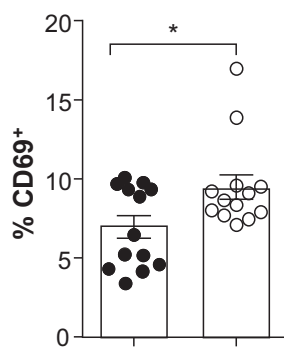

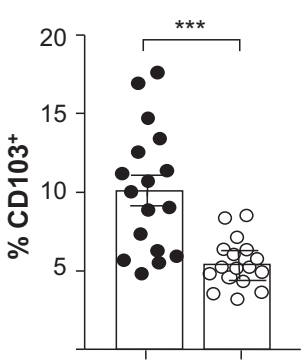

- B16F10E

○ B16F10E-KO

g

$\mathrm{C8}^{+} \mathrm{T}$ cells

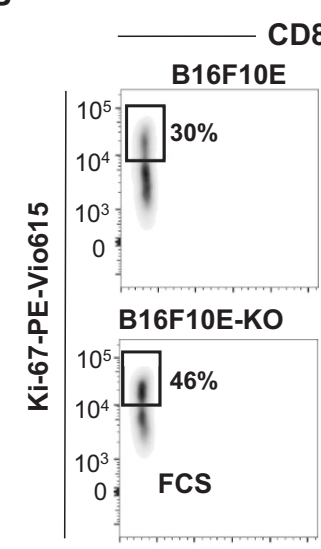

CD8+ $\mathrm{T}$ cells

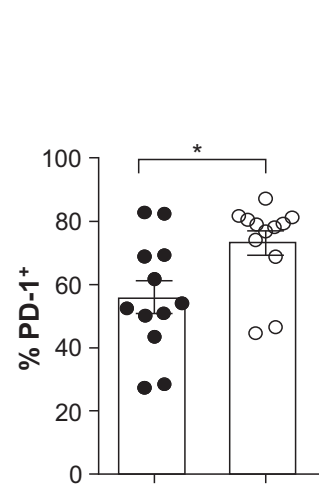

FCS

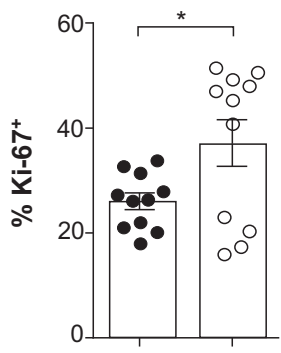

B16F10E

B16F10E-KO anti-tumour CTL response and correlated with an increase in tumour infiltration by proliferative tumour-reactive $\mathrm{CD}^{+} \mathrm{T}$ lymphocytes producing granzyme $\mathrm{B} . \mathrm{CD}^{+} \mathrm{T}$ cell-mediated cytotoxicity against the cognate target correlated with upregulation of MHC-I and PD-L1 on B16F10E-KO cells, excluding an association of the beneficial effect with a reduced PD-L1 expression on $a_{\mathrm{V}}$-knockout tumours as previously reported ${ }^{43}$.
Of note, $a_{\mathrm{V}}$-deficient cancer cells displayed dramatic morphological modifications probably due to alteration in cell-adhesive capacities. However, these changes did not affect tumour cell susceptibility to CTL-mediated killing in vitro, suggesting that in vivo $\alpha_{\mathrm{V}}$ modulation would not have an impact on target cell sensitivity to $\mathrm{CD}^{+} \mathrm{T}$ cells. Preclinical mouse models revealed that TGF- $\beta$ blockade also unleashed an anti-tumour CTL 
Fig. $4 \boldsymbol{\alpha}_{\mathbf{v}}{ }^{\text {high }}$ tumours promote TIL exclusion and decreased T cell proliferation and activation. a Left, B16F10E and B16F10E-KO tumour growth kinetics $(p=0.800)$. Right, tumour weights of B16F10E and B16F10E-KO tumours recovered at day 14 after engraftment $(p=0.846)$. Tumour volumes and tumour weights are given as means \pm SEM of eight mice/group. Data represent one independent experiment out of three. $\mathbf{b}$ The ratio of active versus total TGF- $\beta$ from B16F10E and B16F10E-KO tumours $(n=8)$ was measured ex vivo on day 8 by ELISA $\left({ }^{*} p=0.038\right)$. c Absolute cell counts of CD3 ${ }^{*}\left({ }^{\star} p=0.040\right)$ and $\mathrm{CD}^{+}{ }^{+}$T cells $\left({ }^{*} p=0.034\right)$ infiltrating B16F10E and B16F10E-KO tumours $(n=8)$. Data are from one independent experiment out of three. $\mathbf{d}$ Representative flow cytometry profiles (bi-exponential scale) of the expression of CD62L and CD44 in CD8+ T cells from B16F10E and B16F10E-KO tumours ( $n=8$ ). Right, percentage of CD44 ${ }^{+}$CD62 $\mathrm{L}^{\text {neg }}$ cells among CD8 ${ }^{+}$T cells in B16F10E and B16F10E-KO $\left({ }^{\star * \star} p=0.0006\right)$. e KLRG1 $\left(n=18,{ }^{\star} p=0.014\right), \mathrm{CD} 69(n=13$, $\left.{ }^{\star} p=0.025\right)$ and $\mathrm{CD} 103\left(n=17,{ }^{\star \star \star} p=0.0003\right)$ expression in CD8 ${ }^{+}$T cells infiltrating B16F10E and B16F10E-KO tumours. Data are from two independent experiments out of three. $\mathbf{f}$ Representative flow cytometry profiles of PD-1 expression on CD8 ${ }^{+}$TIL from B16F10E and B16F10E-KO. Right, expression of PD1 on $\mathrm{CD}^{+}{ }^{+} \mathrm{T}$ cells infiltrating B16F10E and B16F10E-KO tumours $\left(n=12,{ }^{\star} p=0.016\right)$. $\mathbf{g}$ Representative profiles of Ki-67 expression in CD8 ${ }^{+} \mathrm{T}$ cells from B16F10E and B16F10E-KO. Right, expression of Ki-67 in CD8 ${ }^{+}$T cells from B16F10E and B16F10E-KO tumours $\left(n=11,{ }^{*} p=0.028\right)$. Data are from two independent experiments out of three. Each symbol represents an individual tumour $(\mathbf{a}-\mathbf{g}$.). Horizontal lines correspond to mean \pm SEM (a, right $-\mathbf{g}$.). Data were calculated with unpaired Student $t$-tests (a, right-g.) and two-way ANOVA (a, left). Source data are provided as a Source Data file.

response, rendering tumours more susceptible to anti-PD-(L) $1^{22}$. Thus, co-administration of blocking anti-TGF- $\beta$ and anti-PD-L1 antibodies facilitated $\mathrm{T}$ cell recruitment and promoted antitumour immunity leading to tumour regression ${ }^{44}$. Selective targeting of LAP-TGF- $\beta$ overcomes primary resistance to ICB by increasing intra-tumoural $\mathrm{CD} 8^{+} \mathrm{T}$ cells and decreasing immunosuppressive myeloid cells ${ }^{42}$. Moreover, simultaneous targeting of TGF- $\beta$ and PD-L1 has been described to enhance anti-tumour activity by increasing the influx and functionality of $\mathrm{CD}^{+} \mathrm{T}$ lymphocytes in the TME ${ }^{45,46}$. However, targeting TGF- $\beta$ and PD1 with specific blocking antibodies had no effect in our in vivo mouse model, suggesting that a minimal level of the cytokine is needed for $\mathrm{T}_{\mathrm{RM}}$ cell formation and control of tumour progression.

TGF- $\beta$ is an important regulator of local immune responses via its participation in the differentiation of $\mathrm{CD}_{103}{ }^{+} \mathrm{CD} 8{ }^{+} \mathrm{T}_{\mathrm{RM}}$ cells in peripheral tissues and solid tumours, at least in part by triggering CD103 expression. Along the same lines, we show that by activating TGF- $\beta$, tumour $\alpha_{\mathrm{V}}$ promotes CD103 expression on activated CD8 ${ }^{+}$ $\mathrm{T}$ lymphocytes in vitro, and that integrin knockout inhibits this process at least in part, by compromising activation of Smad2/3, critical regulators of the ITGAE gene, which encodes $\mathrm{CD} 103^{47}$. Although $\alpha_{\mathrm{V}}$ knockout induced a slight decrease in the frequency of $\mathrm{CD}_{103}{ }^{+} \mathrm{CD} 8{ }^{+} \mathrm{TIL}$ in anti-PD-1-treated mice, an increase in the percentage of $\mathrm{CD} 103^{+} \mathrm{CD} 69^{+} \mathrm{CD} 8{ }^{+} \mathrm{T}_{\mathrm{RM}}$ cells was observed. These data suggest that by inhibiting TGF- $\beta$ activation, $\alpha_{V}$ knockout in anti-PD-1-treated tumours results in recruitment and expansion of $\mathrm{CD}^{+} \mathrm{T}$ cells, and subsequent induction of CD103 on TCRengaged CTL as we previously reported ${ }^{48}$. These $\mathrm{CD} 103{ }^{+} \mathrm{CD} 69^{+} \mathrm{CD}^{+}{ }^{+} \mathrm{T}_{\mathrm{RM}}$ cells may correspond to truly tumourreactive $\mathrm{T}$ cells the differentiation of which is associated with TGF- $\beta$ that might be activated in the TME by a mechanism dependent of MMP on tumour cells or $\alpha_{V}$ integrins on immune cells. Although tumour $\alpha_{\mathrm{V}}$-dependent active TGF- $\beta$ may participate in $\mathrm{CD} 103^{+} \mathrm{CD}^{+}{ }^{+} \mathrm{T}_{\mathrm{RM}}$ differentiation, higher levels of TGF- $\beta$ may compromise $\mathrm{T}$ cell recruitment in tumours and their expansion at the memory phase. We consistently observed in anti-PD-1-treated NSCLC patients that the density of $\mathrm{CD}^{+} \mathrm{CD} 103^{+} \mathrm{T}_{\mathrm{RM}}$ cells in tumours with $\alpha_{\mathrm{V}}$ low profile was higher than in tumours with $\alpha_{\mathrm{V}}$ high.

As opposed to $\mathrm{CD}_{103}{ }^{+} \mathrm{CD} 8{ }^{+} \mathrm{T}$ cells, our in vivo studies showed a strong decrease in the frequency of CD $103^{+}{ }^{+}$FoxP $3^{+} \mathrm{CD} 4{ }^{+}$Treg in $\alpha_{V}$-knockout tumours, suggesting that $\mathrm{CD} 103$ expression in FoxP3 ${ }^{+} \mathrm{CD} 4^{+}$and $\mathrm{CD} 8^{+} \mathrm{T}$ cells is regulated by distinct mechanisms. $\mathrm{CD} 103^{+} \mathrm{CD} 4^{+}$Treg were described as suppressing T-effector cell activation more strongly than their $C D 103^{\text {neg }}$ counterparts, and that silencing TGF- $\beta$ reduced their frequency and suppressive activity ${ }^{49}$. Targeting LAP on Treg cells also promoted anti-tumour immunity by decreasing TGF- $\beta$ production and increasing tumour infiltration with activated $\mathrm{CTL}^{50}$. Consistent with this, we observed that an optimized local anti-tumour CD8 $\mathrm{T}$ cell immunity correlates with a decreased frequency of $\mathrm{CD}_{103}{ }^{+} \mathrm{CD} 4^{+}$Treg cells in anti-PD-1treated- $\alpha_{\mathrm{V}}$-knockout tumours. Blockade of $\alpha_{\mathrm{V}}$ on human Treg cells has also been shown to inhibit Treg-mediated immune suppression by inhibiting TGF- $\beta$ maturation ${ }^{51,52}$. This integrin is also expressed by $\mathrm{CD}_{103}{ }^{+} \mathrm{DC}$ and confers the capacity to generate Treg by activating TGF- $\beta^{53}$. Thus, targeting $\alpha_{V}$ integrin in tumour and immune cells would permit inhibition of Treg generation and promote $\mathrm{CD}^{+} \mathrm{T}$ cell recruitment and effector functions within the TME.

We previously demonstrated that CD103 is directly involved in $\mathrm{T}_{\mathrm{RM}}$ recruitment within epithelial tumour regions, and that TGF$\beta$ enhanced CD103-dependent T cell adhesion and migration and promoted anti-tumour CTL functions ${ }^{54}$. CD103 also participates in $\mathrm{T}_{\mathrm{RM}}$ residency in tumours, and targeting this integrin or TGF$\beta$ has been shown to decrease the number of intra-tumoural $T_{R M}$ cells ${ }^{17,55}$. CD103 favours $\mathrm{T}$ cell retention in epithelial tumour islets through binding to its ligand, the epithelial cell marker E-cadherin ${ }^{54,56}$. Thus, TGF- $\beta$ is involved in the retention of $\mathrm{T}_{\mathrm{RM}}$ at least in part through the induction of CD103 and CD6957. Our in vivo studies showed that $\alpha_{\mathrm{V}}$ knockout combined with PD-1 blockade induced an increase in intra-tumoural granzyme-Bproducing $\mathrm{CD} 03^{+} \mathrm{CD}^{+} 9^{+} \mathrm{CD} 8{ }^{+} \mathrm{T}$ cells with a parallel optimization of CTL-mediated target cell killing. Moreover, blockade of CD103 inhibited growth control of anti-PD-1-treated- $\alpha_{\mathrm{V}^{-}}$ knockout tumours associated with a decrease in T cell-mediated cytotoxicity toward target cells. Thus, by activating TGF- $\beta, \alpha_{\mathrm{V}}$ integrin plays a dual role in regulating anti-tumour $\mathrm{T}$ cell response; on the one hand by controlling $\mathrm{CD} 8^{+} \mathrm{T}_{\mathrm{RM}}$ differentiation and retention in epithelial tumour regions, and on the other, by participating in $\mathrm{T}$ cell exclusion and dysfunction. The capacity of $\alpha_{V}$ on stromal cells in controlling the formation and epithelial residence of CD8 ${ }^{+} \mathrm{T}_{\mathrm{RM}}$ cells by activating TGF- $\beta$ has been demonstrated in healthy tissues ${ }^{58}$. Moreover, the expression of $\alpha_{V}$ by DC has been reported to prepare naïve CD8 ${ }^{+} \mathrm{T}$ cells for the formation of epithelial $\mathrm{T}_{\mathrm{RM}}$ cells ${ }^{36}$. These findings support the hypothesis that $\alpha_{\mathrm{V}}$ on tumour-infiltrating immune cells participate in the formation of $\mathrm{CD}_{103}{ }^{+} \mathrm{CD}^{+}{ }^{+} \mathrm{T}_{\mathrm{RM}}$ in the TME and in regulating $\mathrm{T}$ cell recruitment and functions.

Overall, we conclude that $\alpha_{V}$ on tumour cells shapes the tumour immune infiltrate and dictates the cellular and cytokine components of the TME by activating TGF- $\beta$ and thereby by regulating CD8 $\mathrm{T}$ cell immunity and response to anti-PD-1. This integrin could be considered as a potential biomarker of response to $\mathrm{T}$ cell-based cancer immunotherapies and targeting it may improve the clinical benefit from ICB.

\section{Methods}

Cohorts of treatment-naïve and anti-PD-(L)1-treated NSCLC patients. The treatment-naïve cohort of early-stage NSCLC patients includes a total 
a

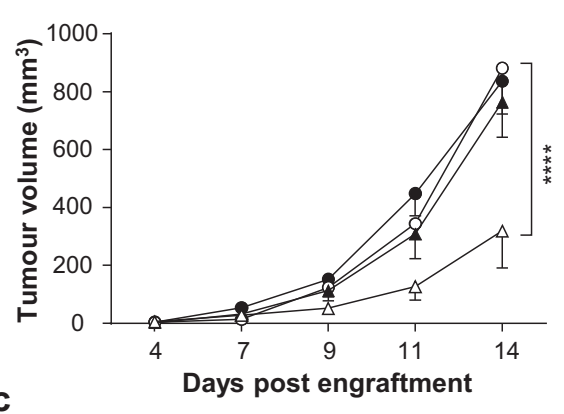

C
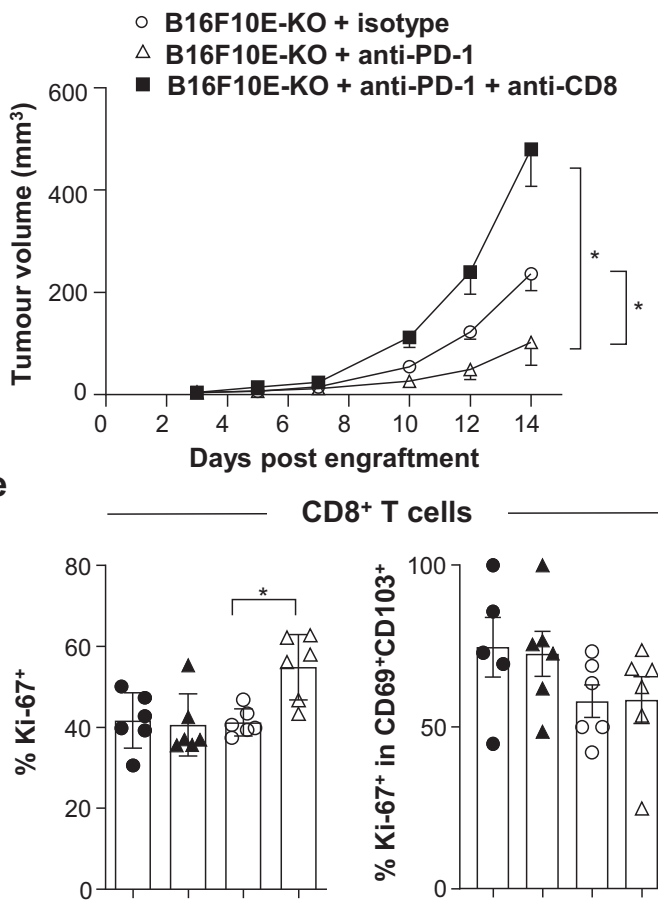

f

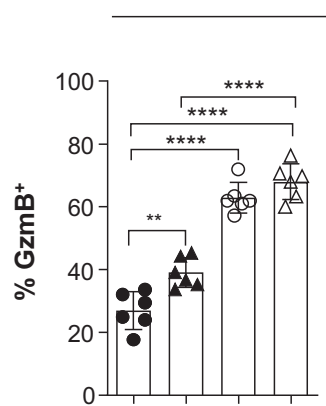

\section{CD8 ${ }^{+} \mathrm{T}$ cells}

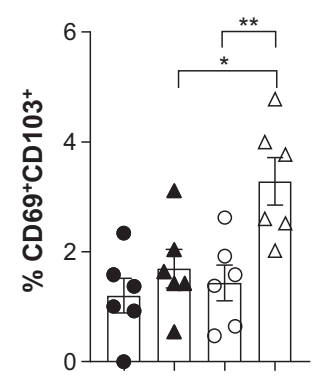

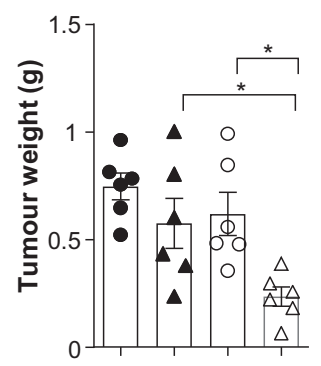

d b

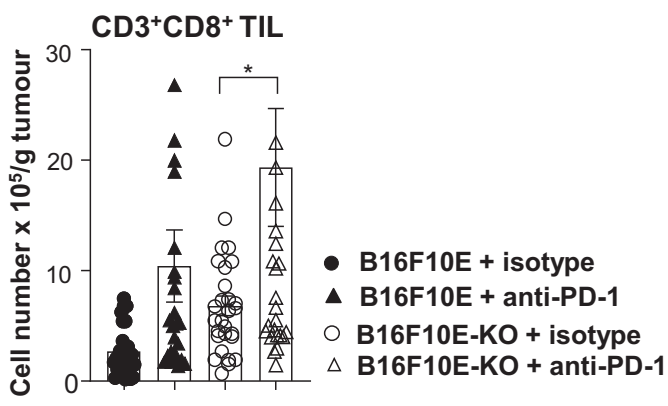

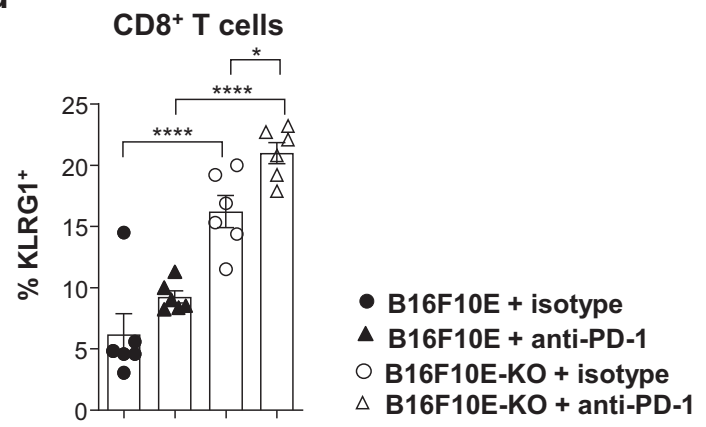

- B16F10E + isotype

A B16F10E + anti-PD-1

O B16F10E-KO + isotype

$\triangle$ B16F10E-KO + anti-PD-1

g
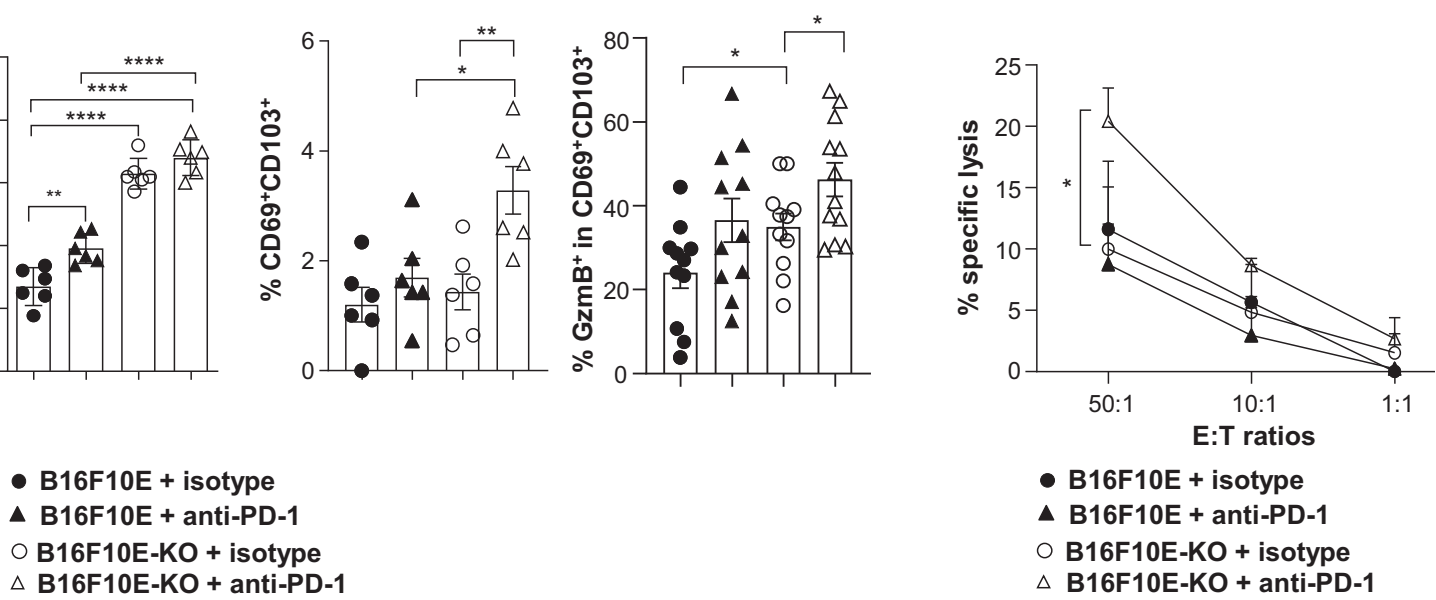

- B16F10E + isotype

$\triangle$ B16F10E + anti-PD-1

O B16F10E-KO + isotype

$\triangle$ B16F10E-KO + anti-PD-1

of 113 tumour samples ${ }^{15}$. The monocentric retrospective study at Gustave Roussy describes a first cohort (cohort 1) of 106 and a second cohort (cohort 2) of 51 advanced NSCLC patients treated between 2012 and 2020, with anti-PD-

(L) 1 administered in a variety of settings. Demographic, clinical, pathological, and molecular data were collected (Supplementary Tables 1 and 2). Radiological assessments were performed every 8 weeks per RECIST v1.1 and per the investigator's discretion. This study was approved by the Institutional Review Board of Gustave Roussy (Commission Scientifique des Essais Thérapeutiques [CSET]) and informed consent from patients was obtained.

Immunohistochemistry staining. IHC was performed on archived FFPE tumour tissue specimens using Ventana Benchmark and Discovery automated platforms. After deparaffinization and epitope retrieval in $\mathrm{CC} 1$ buffer $(\mathrm{pH}=8,36 \mathrm{~min}$ at $95^{\circ} \mathrm{C}$ ), tissue sections were incubated with primary mAb for $a_{\mathrm{V}}$ (clone EPR16800, Abcam ab179475, 1/1000) during $1 \mathrm{~h}$ at room temperature. Amplification and 
Fig. 5 Anti-PD-1 improves tumour growth control of B16F10E-KO. a Growth of B16F10E and B16F10E-KO tumours ( $\left.{ }^{\star \star \star \star} p<0.0001\right)$. Right, weights of tumours recovered at day 14, B16F10E + anti-PD-1 vs. B16F10E-KO+anti-PD-1 ( $\left.{ }^{\star} p=0.023\right)$, B16F10E-KO+isotype vs. B16F10E-KO+ anti-PD-1 ( ${ }^{*} p=0.049$ ). Tumour volumes and weights are given as means \pm SEM $(n=6)$. Data represent one independent experiment out of five. $\mathbf{b}$ Absolute number of CD $8^{+}$ T cells from B16F10E $(n=16)$ and B16F10E-KO $(n=18)$ tumours treated with anti-PD-1 or isotype control $(n=17, \mathrm{~B} 16 \mathrm{~F} 10 \mathrm{E} ; n=19, \mathrm{~B} 16 \mathrm{~F} 10 \mathrm{E}-\mathrm{KO})$. Data are from five independent experiments $\left({ }^{*} p=0.037\right)$. c Growth of B16F10E-KO tumours $(n=6)$. Tumour volumes are given as means \pm SEM. Data are from one independent experiment out of two. B16F10E-KO+iso vs. B16F10E-KO+anti-PD-1 ( $\left.{ }^{*} p=0.043\right)$; B16F10E-KO+anti-PD-1 vs. B16F10E-KO+anti-CD8 $\left({ }^{\star} p=0.020\right)$. d Percentages of KLRG1 ${ }^{+}$cells in $\mathrm{CD} 8+\mathrm{T}$ cells from tumours $(n=6)$ treated with anti-PD-1 or isotype control $\left({ }^{\star} p=0.043,{ }^{* \star \star \star} p<0.0001\right)$. Data are from one independent experiment out of three. e Percentages of Ki-67+ ${ }^{+}$cells among $\mathrm{CD} 8{ }^{+}\left({ }^{*} p=0.012\right)$ and $\mathrm{CD} 69^{+} \mathrm{CD} 103^{+} \mathrm{CD} 88^{+} \mathrm{TIL}$ from B16F10E-KO $(n=6)$ and B16F10E tumours treated with anti-PD-1 $(n=6)$ or isotype control $(n=5)$. Data are from one independent experiment out of three. f Percentages of granzyme B (GzmB) $+\left(\right.$ left, ${ }^{\star \star} p=0.0043,{ }^{\star \star \star \star *} p<0.0001$ ) and CD69+CD103+ (middle, $\left.{ }^{\star} p=0.025,{ }^{* \star} p=0.008\right)$ in $\mathrm{CD} 8{ }^{+} \mathrm{T}$ cells from tumours $(n=6)$ treated with anti-PD-1 or isotype control. One independent experiment out of three is shown. Right, percentages of granzyme $\mathrm{B}^{+}$ cells in $\mathrm{CD}_{69}{ }^{+} \mathrm{CD}_{103}{ }^{+} \mathrm{CD} 8+{ }^{+}$T cells from B16F10E $(n=11)$ and B16F10E-KO $(n=12)$ treated with anti-PD-1 or isotype control $(n=11)$, B16F10E + iso vs. B16F10E-KO+isotype ( $\left.{ }^{*} p=0.046\right) ; B 16 F 10 E-K O+$ isotype vs. B16F10E-KO+anti-PD-1 ( $\left.{ }^{*} p=0.040\right)$. Two independent experiments out of three are included. g. Cytotoxic activity of CD8 ${ }^{+}$TIL isolated from B16F10E and B16F10E-KO tumours treated with anti-PD-1 or isotype control $\left({ }^{\star} p=0.037\right)$. Indicated are the effector-to-target (E:T) ratios. Data are means of three independent experiments. Each symbol represents an individual tumour; horizontal lines correspond to mean \pm SEM (a right, b, d-f.). Data were calculated with one-way ANOVA with Tukey's correction (a right, d, e, $\mathbf{f}$ left, middle), unpaired $t$-test (b, f right, $\mathbf{g}$.), two-way ANOVA for tumour growth $(\mathbf{a}, \mathbf{c})$. Source data are provided as a Source Data file.

detection were performed with an Ultraview kit using amplification and 3,3'-diaminobenzidine as a chromogen. Integrin $\alpha_{\mathrm{V}}$ staining was evaluated by a pathologist as the prominent intensity for each tumour. Tumours were considered $\alpha_{V}{ }^{\text {low }}$ when cancer cells were negative for $\alpha_{V}$ expression $\left(\alpha_{V}{ }^{\text {neg }}\right)$ or when their $\alpha_{V}$ expression level was weaker than on stromal cells and infiltrating immune cells. They were considered $\alpha_{\mathrm{V}}$ high, when $\alpha_{\mathrm{V}}$ expression on more than $75 \%$ of cancer cells was stronger than on stromal and immune cells. Multiplexed fluorescent IHC for $\mathrm{CD}^{+} \mathrm{CD}^{+} 3^{+}$and $\mathrm{CD} 8{ }^{+} \mathrm{CD} 103^{\text {neg }}$ lymphocytes was performed by sequential staining of a single tissue section with anti-CD8 (clone SP16, Spring Bioscience M3160, 1/200), anti-CD103 (clone EPR4166-2, Abcam ab129202, 1/200), and anticytokeratin (clones AE1/AE3, Dako GA05361-2, 1/100) ${ }^{14}$. For each staining, the HRP-conjugated amplification system was associated with a tyramide-coupled fluorophore: Opal 690, Opal 250, and Opal 570, respectively. Multispectral fluorescent images were captured using the Vectra 3 microscope (PerkinElmer) and regions of interest were selected. Image analysis using InForm software (PerkinElmer) included spectral unmixing, nuclei detection based on DAPI staining, and cell segmentation followed by cell phenotyping for identification of cell populations defined by the combination of individual markers. The density (number of cells per square $\mathrm{mm}$ ) of $\mathrm{CD}^{+}, \mathrm{CD}^{+} \mathrm{CD}^{+} 3^{+}$, and $\mathrm{CD} 8^{+} \mathrm{CD} 103^{\text {neg }}$ was determined for each tumour sample in the total tumour area based on tissue segmentation. Results from image analysis were validated for all cases.

Patient outcome and IHC data analyses. OS for treatment-naïve patients was calculated from the date of primary tumour resection until death due to any cause. PFS for anti-PD-(L)1-treated patients was calculated from the date of the first immunotherapy administration until disease progression or death due to any cause, whichever occurred first. The best cut-point for total $\mathrm{CD} 8^{+}, \mathrm{CD}^{+} \mathrm{CD} 103^{+}$, and $\mathrm{CD} 8^{+} \mathrm{CD} 103^{\text {neg }}$ TIL was assessed using the log-rank maximization $\operatorname{method}^{59}$. Survival analyses were performed using the Kaplan-Meier method and the logrank test. All $p$-values inferior to 0.05 were considered statistically significant.

A Cox proportional hazards regression model was used to evaluate independent prognostic factors for OS and PFS. Variables included in the final multivariate model were selected according to their clinical relevance and statistical significance in univariate analysis ( $p$-value cut-off $=0.10$ ). The proportional hazard hypothesis was verified with the Schoenfeld residual method. Predictive factors of disease control were tested with logistic regression in univariate and multivariate analyses. The alpha level was 5\%. Statistical analyses were performed with RStudio v1.1.463 (free software environment for statistical computing and graphics).

TCGA data analysis. Using http://kmplot.com, analysis of gene-expression datasets derived from NSCLC patients was performed on a group of stage I surgically managed patients who did not receive radiotherapy or chemotherapy $(n=70)$. Gene-expression data were automatically computed to generate Kaplan-Meier plots (doi: 10.1371/journal.pone.0082241) ${ }^{60}$.

Quantitative RT-PCR. Total RNA was immediately extracted from human and murine samples using TRIzol reagent (Invitrogen). cDNA was synthesized with the Maxima First Strand cDNA Synthesis Kit (ThermoFischer Scientific). qRT-PCR was performed on a Step-One Plus (Applied Biosystems) using Maxima SYBR Green Master Mix (ThermoFischer Scientific). Expression levels of transcripts were normalized to $18 S$ expression. PCR primers and probes for human (ITGAV, ITGB1, ITGB3, ITGB5, ITGB6, ITGB8, TGFB1, and 18S) and mouse (itgb1, itgb3, itgb5, itgb6, itgb8, and 18S) genes (Supplementary Table 6) were provided by Sigma-Aldrich and used according to the manufacturer's recommendations.
Antibodies and flow cytometry. For human tumour cell surface and intracellular staining, anti- $\alpha_{V}$ (clone NKI-M9, BioLegend 327908, 1/100), - $\beta_{6}$ (clone 437211, R\&D Systems MAB4155, 1/100), $-\beta_{8}$ (clone 416922, R\&D Systems MAB4775, 1 / 100 ), anti-E-cadherin (clone 67A4, BioLegend 324106, 1/200) and -EpCAM (clone 9C4, BioLegend 324207, 1/200) mAb were used. Cell surface and intracellular staining of mouse cells was performed on single-cell suspensions using antibodies specific to the following molecules: CD51 (integrin $a_{V}$, clone RMV-7, BioLegend 104106, 1/200), E-cadherin (clone DECMA-1, BioLegend 147307, 1/200), H2-K H2- $\mathrm{D}^{\mathrm{b}}$ (clone 28-8-6, BioLegend 114605, 1/200), PD-L1 (clone 10F.9G2, BioLegend $124313,1 / 100$ ), integrin $\beta 5$ (clone KN52, ThermoFischer Scientific 11-0497$41,1 / 50$ ), integrin $\beta 3$ (clone 909114, R\&D systems FAB8557A, 1/100), CD3 (clone 17A2, BioLegend 100241, 1/200), CD4 (clone RM4-5, BioLegend 100536, 1/200), FoxP3 (clone FJK-16S, Thermo Ficher 35-5773-80, 1/100), CD8a (clone REA601, Miltenyi 130-109-252, 1/20), CD62L (clone MEL-14, BioLegend 104405, 1/200), CD44 (clone IM7, BioLegend 103030, 1/100), PD-1 (clone 29F.1A12, BioLegend 135223, 1/100), CD69 (clone H1.2F3, BioLegend 104512, 1/100), CD103 (clone 2E7, BioLegend 121418, 1/200), KLRG1 (clone 2F1, BioLegend 138407, 1/100), Ki67 (clone REA183, Miltenyi 130-120-556, 1/11), IFN- $\gamma$ (clone XMG1.2 BioLegend $505825,1 / 50$ ), granzyme B (clone GB11, BioLegend 515403, 1/50), pSmad2/3 (clone 072-670, BD 562586, 1/20), MHC-II (clone REA528, Miltenyi 130-108-004, $1 / 20$ ) and CD11c (clone N418, BioLegend 117321, 1/200). Dead cells were excluded using the Live/Dead Fixable Blue Dead Cell Stain Kit (Invitrogen 186684). Staining of MMP14 was performed with specific mAb (clone EP1264Y, Abcam ab51074, 1) 200) followed by secondary antibody staining (goat anti-rabbit IgG Abcam ab150077, 1/200).

For intracellular staining, cells were fixed, permeabilized with the FoxP3 staining buffer set according to the manufacturer's instructions (eBioscience 00-5523-00). Flow cytometry was conducted on an LSR Fortessa (BD) and analyzed using FlowJo software V10 (Tree Star).

Human PBMC and lung TIL. HD blood samples were collected from the French blood bank (Etablissement Français du Sang (EFS); agreement number $N^{\circ} 12 / E F S /$ 079. PBMC were isolated by a Ficoll-Hypaque gradient.

NSCLC tumours were obtained from the Centre chirurgical Marie Lannelongue. For freshly isolated TIL and cancer cells, human lung tumours were dissociated mechanically and enzymatically using a Tumour Dissociation Kit (Miltenyi, 130095-929). Mononuclear cells were then isolated by a Ficoll-Hypaque gradient. Tumour cells were isolated by magnetic separation using Tumour Cell Isolation Kit (Miltenyi, 130-108-339). Healthy donors and patients provided their written informed consent prior to inclusion in this study. All human experiments were approved by the Institutional Review Board of Gustave Roussy.

Human tumour cell lines and CTL clone. The IGR-B2 cell line and the autologous B90 CTL clone were derived from patient Bla large cell carcinoma ${ }^{30}$. The allogeneic NSCLC cell lines IGR-Pub, IGR-Heu, ADC-Coco, ADC-Tor, and ADC-Let were derived from tumour specimens in one of our laboratories. H1355 (adenocarcinoma), H460, and H1155 (large cell carcinoma) were a generous gift from Dr. S Rogers (Brigham and Women's Hospital, Boston, MA), and A549 (adenocarcinoma), SK-Mes, Ludlu (squamous cell carcinoma, SCC) and DMS53 (small-celllung carcinoma, SCLC) were purchased from the European Collection of Cell Cultures $^{30}$. Lung tumour cells lines were grown in DMEM/F-12 medium (ThermoFischer Scientific) supplemented with $10 \%$ fetal calf serum (FCS), $1 \%$ Ultroser G (Pall), $1 \mathrm{mM}$ sodium pyruvate, and antibiotics $(50 \mathrm{U} / \mathrm{ml}$ penicillin and $50 \mu \mathrm{g} / \mathrm{ml}$ streptomycin). All the cell lines are mycoplasma-free and were regularly tested for 
a

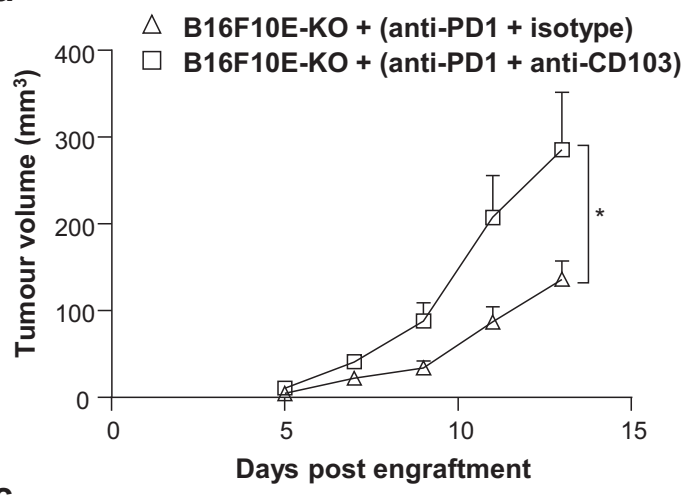

C

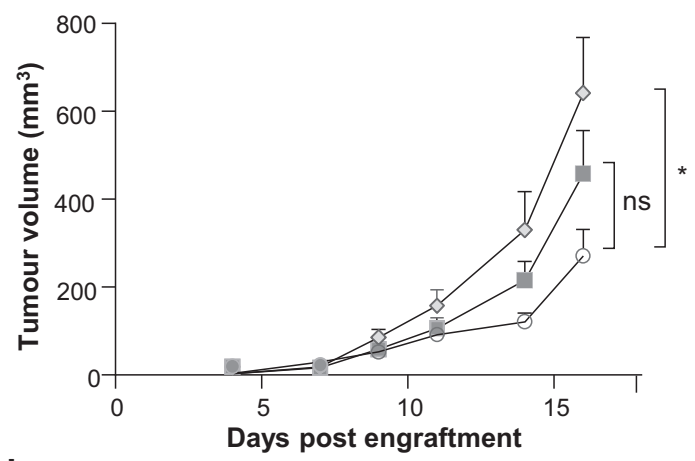

d

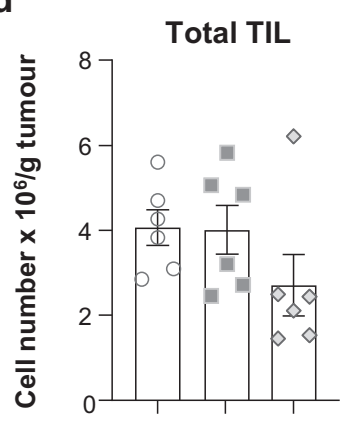

b
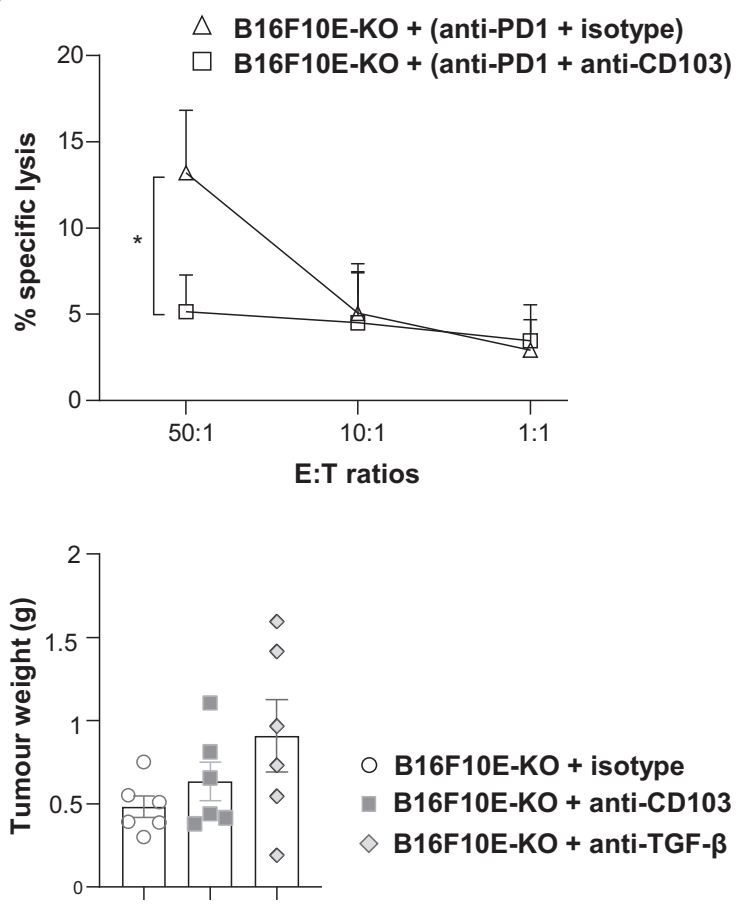

O B16F10E-KO + isotype

- B16F10E-KO + anti-CD103

$\diamond$ B16F10E-KO + anti-TGF- $\beta$ e

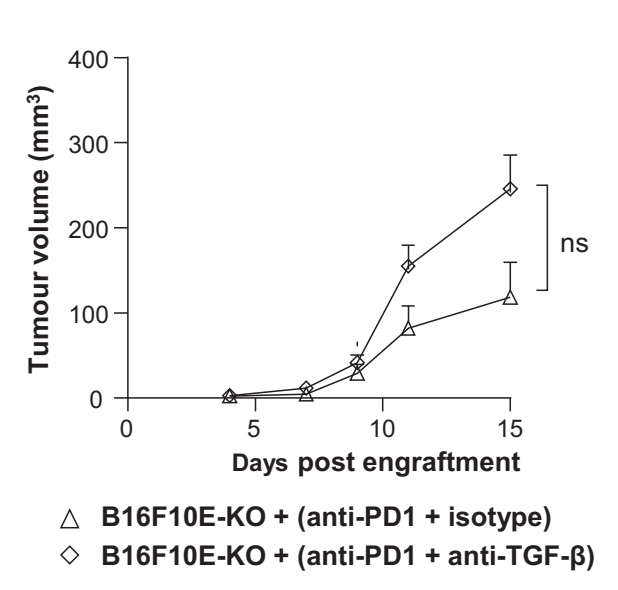

$\triangle$ B16F10E-KO + (anti-PD1 + isotype)

$\diamond$ B16F10E-KO + (anti-PD1 + anti-TGF- $\beta$ )

e

mycoplasma contamination. We regularly authenticate IGR-B2 cell line by testing recognition by autologous $B 90$ CTL clone, and HLA-A2 expression.

Transfection of IGR-B2 with TGF- $\beta$ and knockout of $\boldsymbol{\alpha}_{\mathbf{v}}$ subunit. The IGR-B2 NSCLC cell line was stably transfected with pcDNA3.1-hTGF $\beta$-LAP plasmid (from one of our laboratories) using Lipofectamine 2000 (ThermoFischer Scientific) according to the manufacturer's instructions. The cell line obtained was cloned,
Total TIL
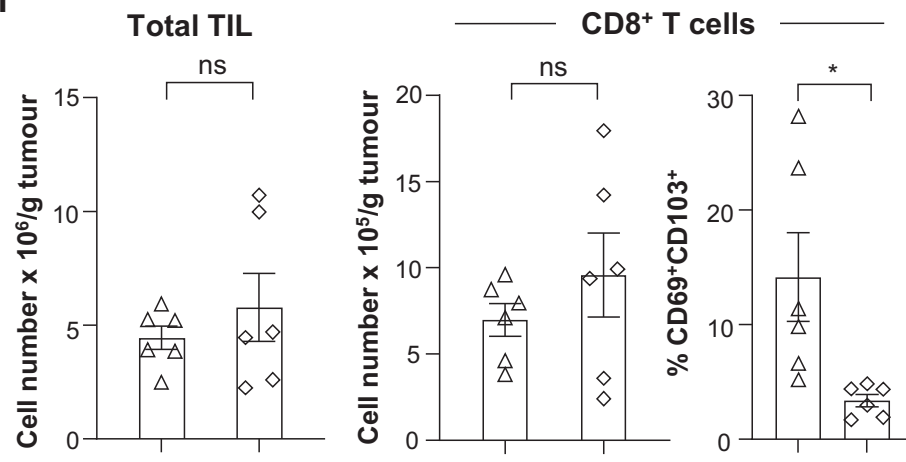
Fig. 6 Effect of anti-CD103 and TGF- $\beta$ neutralizing mAb on tumour growth and PD-1 blockade therapy in B16F10E-KO tumours. a Neutralizing antiCD103 mAb inhibits the effect of anti-PD-1. Growth of B16F10E-KO tumours, treated with anti-PD-1 and then receiving anti-CD103 blocking mAb (i.t.) or isotype control. Tumour volumes are given as means \pm SEM of six mice/group ( ${ }^{*} p=0.043$ ). Data are from two independent experiments out of two. b Cytotoxic activity of CD8 ${ }^{+}$TIL isolated from B16F10E-KO tumours $(n=3)$ treated with anti-PD-1 (i.p.) plus isotype control (i.t.) or anti-PD-1 plus antiCD103 (i.t.). Cytotoxicity against B16F10E-KO tumour cells was determined by a conventional ${ }^{51} \mathrm{Cr}$ release assay at indicated E:T ratios. Data are from one independent experiment out of two ( $\left.{ }^{*} p=0.030\right)$. c Effects of anti-TGF- $\beta$ and anti-CD103 neutralizing mAb on tumour growth. Mice were engrafted with B16F10E-KO and then treated with anti-TGF- $\beta$, anti-CD103, or isotype control (i.t.). Tumour volumes are given as means \pm SEM of six mice/group. Right, tumour weights of B16F10E-KO $(n=6)$ recovered at day $17\left({ }^{*} p=0.024\right)$. d Left, absolute cell counts of total TIL and right, CD8 ${ }^{+} \mathrm{T}$ cells infiltrating B16F10E-KO tumours treated with anti-TGF- $\beta$, anti-CD103, or isotype control $(n=6)$. e Effects of anti-TGF- $\beta$ neutralizing mAb on PD-1 blockade. Growth of B16F10E-KO tumours, treated with anti-PD-1 and then received anti-TGF- $\beta$ blocking mAb (i.t.) or isotype control. Tumour volumes are given as means \pm SEM of six mice/group $(p=0.196)$. $\mathbf{f}$ Left, absolute counts of total TIL in B16F10E-KO tumours treated with anti-PD-1 plus anti-TGF- $\beta$ or anti-PD-1 plus isotype control $(p=0.418)$. Middle panel, absolute counts of CD8 ${ }^{+}$T cells $(p=0.343)$ and right, percentages of $C D 69^{+} \operatorname{CD103}{ }^{+}\left({ }^{*} p=0.020\right)$ among $\mathrm{CD}^{+}+\mathrm{T}$ cells from B16F10E-KO tumours treated with anti-PD-1 mAb (i.p.) plus anti-TGF- $\beta$ (i.t.) or anti-PD-1 plus isotype control ( $n=6$ ). Each symbol represents an individual tumour; horizontal lines correspond to mean \pm SEM (c right, $\mathbf{d}, \mathbf{f}$ ). Data were calculated with unpaired $t$-test (a-c, e, $\mathbf{f}$ ) and oneway ANOVA with Tukey's correction (c right, d.). Source data are provided as a Source Data file.

(10 $\mu \mathrm{g} / \mathrm{ml}$, Sigma-Aldrich). The generated cell line was tested for $\alpha_{\mathrm{V}}$ knockout by FACS, and then cloned by cell sorting. A clone, thereafter named IGR-B2T-KO, was retained for further studies.

B16F10 cell line and $\boldsymbol{\alpha}_{v}$ knockout clone. The B16F10 melanoma cell line $\left(\mathrm{H}-2^{\mathrm{b}}\right)$ was purchased from the American Type Culture Collection (ATCC CRL-6475) and grown in DMEM-F12 medium supplemented with $10 \%$ FCS, $2 \mathrm{mM}$ L-glutamine, $1 \mathrm{mM}$ sodium pyruvate, and antibiotics. It was stably transfected with pcDNA-Ecadherin plasmid (gift from Lionel Larue, Institut Curie, Orsay) and a clone, named B16F10E, was isolated and used in all experiments. Homozygous knockout of $\alpha_{\mathrm{V}}$ expression was performed as above using the CRISPR-Cas9 technology (sc-421169 and sc-421169-HDR), and a clone, named B16F10E-KO, was selected for further experiments.

Quantification of TGF- $\beta$ in conditioned media and tumours. Human and mouse tumour cells were cultured in complete medium, and for an additional $24 \mathrm{~h}$ in serum-free medium. The CM was then harvested and concentrated $75 \times$ using Amicon Ultra Centrifugal Filters-10 K (Merck). CM was used to measure the concentration of total TGF- $\beta$ by ELISA using human and mouse TGF- $\beta$ DuoSet ELISA kits (DY240 and DY1679, ThermoFischer Scientific). For MMP activity inhibition, tumour cells were cultured in the presence of the MMP inhibitor GM6001 (Millipore, CC1010, 1/1000) or DMSO control, and four days later, CM was harvested.

Activation of LAP-TGF- $\beta$ by parental and $\alpha_{\mathrm{V}}$-knockout tumour cells was evaluated using the thymic mink lung epithelial cells Mu.1LV (gift from Céline Prunier, Centre de Recherche Saint Antoine, Paris), cultured with $24 \mathrm{~h}$ CM. First, Mu.1LV cells were resuspended in DMEM/F12 medium supplemented with $10 \%$ FCS, plated for $24 \mathrm{~h}$, and then transfected with the pGL3-(CAGA)9-Lux reporter construct, which contains concatemerized CAGA elements that bind Smad 3 and Smad 4 complexes and are transactivated by both TGF- $\beta$ and Smad3/4 expression ${ }^{61}$. Twenty-four hours after Mu.1LV transfection, $\mathrm{CM}$ was added to serum-free Mu.1LV cells, and cells were lysed and assayed for luciferase activity using Bright Glo Luciferase Assay System (Promega). For quantification of active and total TGF- $\beta$ in mouse B16F10E and B16F10E-KO, tumours were crushed and rinsed with phosphate-buffered saline (PBS), and the solution was used for active and total TGF- $\beta$ quantification (DY1679 DuoSet ELISA kit, ThermoFischer Scientific).

Induction of CD103 on activated human CD8 T cells. Plates were coated with 1 $\mu \mathrm{g} / \mathrm{ml}$ of anti-CD3 blocking $\mathrm{mAb}$ (clone OKT3, BioLegend 317301, 1/1000) for 24 h at $4{ }^{\circ} \mathrm{C} .5 \times 10^{5} \mathrm{PBMC} /$ well were added and cultured for 3 days at $37^{\circ} \mathrm{C}$ and $5 \%$ $\mathrm{CO}_{2}$ with CM from B16F10E or B16F10E-KO and IGR-B2T or IGR-B2T-KO cells in the absence or presence of a low $(1 \mathrm{ng} / \mathrm{ml})$ or high $(5 \mathrm{ng} / \mathrm{ml})$ dose of rTGF- $\beta$ (240-B-002, R\&D Systems) or blocking anti-TGF- $\beta$ mAb (clone 1D11.16.8, BioXcell BE0057, $10 \mu \mathrm{g} / \mathrm{ml}$ ). Expression of CD103 (clone Ber-ACT8, BioLegend $350204,1 / 100$ ) and KLRG1 (clone 13F12F2, ThermoFicher 12-9488-42, 1/100) on $\mathrm{CD}^{+}{ }^{\mathrm{CD}} 8^{+}$cells $(\mathrm{CD} 3$ : clone UCHT1, BioLegend 300463, 1/200; CD8a: clone RPA-T8, BioLegend 301012, 1/200) was then determined by flow cytometry.

PLA of $\alpha_{\mathbf{v}}$ integrin and LAP-TGF- $\beta$ interaction. The green PLA signal was observed for $\alpha_{\mathrm{V}}$ and LAP-TGF- $\beta$ interaction. PLA was performed on fixed and permeabilized tumour cells according to the manufacturers' instructions (DuoLink In Situ Detection Reagents Green, Sigma Aldrich). After blocking, anti- $\alpha_{\mathrm{V}}$ (clone EPR16800, Abcam ab179475, 1/100) and anti-LAP-TGF- $\beta$ (clone TW7-16B4, BioLegend $141402,1 / 100$ ) antibodies were used. PLA-minus and PLA-plus probes, containing the secondary antibodies conjugated with oligonucleotides (dilution in Antibody diluent $1 / 5$ ), were added and incubated for $1 \mathrm{~h}$ at $37^{\circ} \mathrm{C}$. After hybridization, oligonucleotide ligation and a rolling circular amplification were performed. Cell membranes were stained with WGA red conjugate (Thermo Fisher Scientific W21405, 1/1000), nuclei with Fluoromount-G mounting media containing DAPI (eBioscience), and then analyzed with a confocal microscope SP8 (Leica). The number of PLA signals, marked as green dots on the cell surface, was counted in 25-30 fields containing 500-600 cells, by image analysis (Icy, http://icy.bioimageanalysis.org/ download/, v2).

In vitro cell proliferation assay. Tumour cells were labelled with $5 \mu \mathrm{M}$ Carboxyfluorescein Diacetate Succinimidyl Ester (CFSE) dye (Stemcell Technologies) for $5 \mathrm{~min}$ at $37^{\circ} \mathrm{C}$. Cells were then washed twice with FCS-free medium and cultured for 6 days. The proliferation index was calculated every other day by flow cytometric analysis using ModFit $\mathrm{LT}^{\mathrm{m}}$ programme v5.0.

In vivo experiments. Animal experiments were performed in accordance with Gustave Roussy's relevant ethical regulations for animal testing and research. This study received ethical approval from the institutional animal committee (CEEA no. 026: 2018-056-16280) after receiving the legal approval from French Minister of Higher Education, Research and Innovation under the procedure number APAFIS\#16281-2018072515064652v2. Female C57BL/6 mice were purchased from Envigo. The female athymic nude Crl:NU(NCr)-Foxn ${ }^{\text {nu }}$ mice ( 6 weeks old) were inbred in-house. For each experiment, groups of four to eight mice, 7-9 weeks of age received $2 \times 10^{5}$ tumour cells subcutaneously in the right flank. Tumour volume was measured using a calliper every second day and estimated using the following formula: $\pi / 6 \times$ length $\times$ width $\times$ thickness $\left(\mathrm{mm}^{3}\right)$. The mice were sacrificed when the tumour size exceeded the acceptable institutional limit of $2000 \mathrm{mM}^{3}$ by $\mathrm{CO}_{2}$ inhalation.

For TIL isolation, tumours were harvested at day 14 and digested for $30 \mathrm{~min}$ at $37^{\circ} \mathrm{C}$ according to the Tumour Dissociation kit protocol (130-096-730, Miltenyi). Tumours were crushed on $100 \mu \mathrm{m}$ cell strainers and washed twice with PBS $2 \%$ FCS. Single-cell suspensions were enriched for $\mathrm{CD}_{4} 5^{+}$or $\mathrm{CD} 8^{+}$cells using antiCD45 or anti-CD8 microbeads (130-052-301 or 130-117-044, Miltenyi), and then purified using the POSSEL2 programme on MultiMACS. The positive fraction was recovered for TIL analysis and the negative fraction for tumour cell analysis by flow cytometry and ex vivo cytotoxicity assay.

For in vivo blockade with neutralizing $\mathrm{mAb}$, mice received i.p. $100 \mu \mathrm{g} /$ mouse of anti-CD8 (Bio-X-Cell BE0061; clone 2.43), intra-tumoural (i.t.) $50 \mu \mathrm{g} /$ mouse of anti-CD103 (Bio-X-Cell BE0026; clone M290), i.t. $25 \mu \mathrm{g} /$ mouse of anti-TGF- $\beta$ (Bio-X-Cell BE0057; clone 1D11.16.8) and/or $200 \mu \mathrm{g} /$ mouse of anti-PD-1 (Bio-XCell BE0146; clone RMP1-14) mAb or isotype control (Bio-X-Cell BE0089: IgG2a, clone 2A3; Bio-X-Cell BE0090: IgG2b, clone LTF-2; Bio-X-Cell BE0083: IgG1, clone MOPC-21). For tumour outgrowth experiments with anti-PD-1, mice were treated on days 4,7 , and 11 after tumour inoculation, whereas with anti-CD8 and/ or anti-PD-1, mice were treated on days $4,7,10$, and 13 . For experiments with antiCD103 and/or anti-PD-1, mice were treated on days $4,7,11$, and 15, whereas for experiments with anti-TGF- $\beta$ and/or anti-PD-1, mice were treated on days $4,8,11$, and 14 . TIL were sorted and analyzed on day 14 or 15 . For experiments with antiCD103, anti-TGF- $\beta$, and/or anti-PD-1, mice were treated on days $4,7,11$, and 14 . TIL were sorted and analyzed on day 15 or 17 .

In vitro cytotoxicity experiments. The cytotoxic activity of B90 CTL clone against autologous IGR-B2, IGR-B2T, and IGR-B2T-KO tumour cells was measured using a conventional 4 -h chromium $\left({ }^{51} \mathrm{Cr}\right)$ release assay ${ }^{30}$. For cytotoxicity with mouse TIL, $\mathrm{CD}_{4} 5^{+}$cells were isolated and cultivated overnight in a medium containing $50 \mathrm{U}$ IL-2. CD8 ${ }^{+} \mathrm{T}$ cells were purified using microbeads and co-cultured for $4 \mathrm{~h}$ with syngeneic ${ }^{51} \mathrm{Cr}$-labelled B16F10E or B16F10E-KO tumour cells. 
Statistical analysis. Statistical significance was determined with the unpaired or paired Student $t$-test, Welch's $t$-test, Mann-Whitney $t$-test, one-way analysis of variance (ANOVA) test with Tukey's correction, and two-way ANOVA. Statistical analyses were performed with GraphPad Prism software V8 (GraphPad Software, Inc., San Diego, CA, USA).

Reporting summary. Further information on research design is available in the Nature Research Reporting Summary linked to this article.

\section{Data availability}

The authors state that all data generated during this study are included in the article and its Supplementary Information file and are available from the corresponding author upon reasonable request. The data included in this manuscript were not deposited on public websites but are accessible in a supplementary file containing flow cytometry and immunohistochemistry raw data. Source data are provided with this paper. A Reporting Summary for this article is available as a Supplementary file. The use of publicly available data from lung cancer cohorts were consulted on the website https://kmplot.com/ analysis/index.php?p=service\&cancer=lung, under the specific data product name: KM Plotter-Lung Cancer. Source data are provided with this paper.

Received: 9 August 2020; Accepted: 29 July 2021;

Published online: 01 September 2021

\section{References}

1. Borghaei, H. et al. Nivolumab versus docetaxel in advanced nonsquamous non-small-cell lung cancer. N. Engl. J. Med. 373, 1627-1639 (2015).

2. Zaretsky, J. M. et al. Mutations associated with acquired resistance to PD-1 blockade in melanoma. N. Engl. J. Med. 375, 819-829 (2016).

3. Patel, S. J. et al. Identification of essential genes for cancer immunotherapy. Nature 548, 537-542 (2017).

4. Sucker, A. et al. Acquired IFNgamma resistance impairs anti-tumor immunity and gives rise to T-cell-resistant melanoma lesions. Nat. Commun. 8, 15440 (2017).

5. Gao, J. et al. Loss of IFN-gamma pathway genes in tumor cells as a mechanism of resistance to anti-CTLA-4 therapy. Cell 167, 397-404 (2016). e399.

6. Shin, D. S. et al. Primary resistance to PD-1 blockade mediated by JAK1/2 mutations. Cancer Disco. 7, 188-201 (2017).

7. Pai, C. S. et al. Clonal deletion of tumor-specific T cells by interferon-gamma confers therapeutic resistance to combination immune checkpoint blockade. Immunity 50, 477-492 e478 (2019).

8. Tumeh, P. C. et al. PD-1 blockade induces responses by inhibiting adaptive immune resistance. Nature 515, 568-571 (2014).

9. Gros, A. et al. PD-1 identifies the patient-specific CD8(+) tumor-reactive repertoire infiltrating human tumors. J. Clin. Invest. 124, 2246-2259 (2014)

10. McGranahan, N. et al. Clonal neoantigens elicit T cell immunoreactivity and sensitivity to immune checkpoint blockade. Science 351, 1463-1469 (2016).

11. Duhen, T. et al. Co-expression of CD39 and CD103 identifies tumor-reactive CD8 T cells in human solid tumors. Nat. Commun. 9, 2724 (2018)

12. Parkhurst, M. et al. Isolation of T-cell receptors specifically reactive with mutated tumor-associated antigens from tumor-infiltrating lymphocytes based on CD137 expression. Clin. Cancer Res. 23, 2491-2505 (2017).

13. Amsen, D., van Gisbergen, K., Hombrink, P. \& van Lier, R. A. W. Tissueresident memory $\mathrm{T}$ cells at the center of immunity to solid tumors. Nat. Immunol. 19, 538-546 (2018).

14. Corgnac, S. et al. CD103(+)CD8(+) TRM cells accumulate in tumors of anti$\mathrm{PD}$-1-responder lung cancer patients and are tumor-reactive lymphocytes enriched with Tc17. Cell Rep. Med. 1, 100127 (2020).

15. Djenidi, F. et al. CD8+CD103+ tumor-infiltrating lymphocytes are tumorspecific tissue-resident memory $\mathrm{T}$ cells and a prognostic factor for survival in lung cancer patients. J. Immunol. 194, 3475-3486 (2015).

16. Ganesan, A. P. et al. Tissue-resident memory features are linked to the magnitude of cytotoxic T cell responses in human lung cancer. Nat. Immunol. 18, 940-950 (2017)

17. Nizard, M. et al. Induction of resident memory $\mathrm{T}$ cells enhances the efficacy of cancer vaccine. Nat. Commun. 8, 15221 (2017).

18. Clarke, J. et al. Single-cell transcriptomic analysis of tissue-resident memory T cells in human lung cancer. J. Exp. Med. 216, 2128-2149 (2019).

19. Edwards, J. et al. CD103(+) tumor-resident CD8(+) T cells are associated with improved survival in immunotherapy-naive melanoma patients and expand significantly during anti-PD-1 treatment. Clin. Cancer Res. 24, 3036-3045 (2018).

20. Wahl, S. M. Transforming growth factor beta: the good, the bad, and the ugly. J. Exp. Med. 180, 1587-1590 (1994).
21. Thomas, D. A. \& Massague, J. TGF-beta directly targets cytotoxic T cell functions during tumor evasion of immune surveillance. Cancer Cell $\mathbf{8}$, 369-380 (2005)

22. Tauriello, D. V. F. et al. TGFbeta drives immune evasion in genetically reconstituted colon cancer metastasis. Nature 554, 538-543 (2018).

23. Gonzalez-Molina J. et al MMP14 in sarcoma: a regulator of tumor microenvironment communication in connective tissues. Cells 8, 991 (2019).

24. Karsdal, M. A. et al. Matrix metalloproteinase-dependent activation of latent transforming growth factor-beta controls the conversion of osteoblasts into osteocytes by blocking osteoblast apoptosis. J. Biol. Chem. 277, 44061-44067 (2002).

25. Dong, X. et al. Force interacts with macromolecular structure in activation of TGF-beta. Nature 542, 55-59 (2017).

26. Campbell, M. G. et al. Cryo-EM reveals integrin-mediated TGF-beta activation without release from latent TGF-beta. Cell 180, 490-501 (2020). e416.

27. Takasaka, N. et al. Integrin alphavbeta8-expressing tumor cells evade host immunity by regulating TGF-beta activation in immune cells. JCI Insight $\mathbf{3}$, e122591 (2018).

28. Wu, T. C. et al. Reprogramming tumor-infiltrating dendritic cells for CD103+ CD8+ mucosal T-cell differentiation and breast cancer rejection. Cancer. Immunol. Res. 2, 487-500 (2014).

29. Mackay, L. K. et al. T-box transcription factors combine with the cytokines TGF-beta and IL-15 to control tissue-resident memory T cell fate. Immunity 43, 1101-1111 (2015).

30. Le Floc'h, A. et al. Alpha E beta 7 integrin interaction with E-cadherin promotes antitumor CTL activity by triggering lytic granule polarization and exocytosis. J. Exp. Med. 204, 559-570 (2007).

31. Leclerc, M. et al. Regulation of antitumour CD8 T-cell immunity and checkpoint blockade immunotherapy by Neuropilin-1. Nat. Commun. 10, 3345 (2019).

32. Alday-Parejo, B., Stupp, R. \& Ruegg, C. Are integrins still practicable targets for anti-cancer therapy? Cancers 11, 978 (2019).

33. Madala, S. K. et al. Inhibition of the alphavbeta6 integrin leads to limited alteration of TGF-alpha-induced pulmonary fibrosis. Am. J. Physiol. Lung Cell Mol. Physiol. 306, L726-L735 (2014).

34. Brown, N. F. \& Marshall, J. F. Integrin-mediated TGFbeta activation modulates the tumour microenvironment. Cancers 11, 1221 (2019).

35. Wang, $\mathrm{H}$. et al. Integrin subunit alpha $\mathrm{V}$ promotes growth, migration, and invasion of gastric cancer cells. Pathol. Res. Pract. 215, 152531 (2019).

36. Mani, V. et al. Migratory DCs activate TGF-beta to precondition naive CD8(+) T cells for tissue-resident memory fate. Science 366, eaav5728 (2019).

37. Zuo, H. iRGD: a promising peptide for cancer imaging and a potential therapeutic agent for various cancers. J. Oncol. 2019, 9367845 (2019).

38. Aksorn, N. \& Chanvorachote, P. Integrin as a molecular target for anti-cancer approaches in lung cancer. Anticancer Res. 39, 541-548 (2019).

39. Cheuk, I. W. et al. ITGAV targeting as a therapeutic approach for treatment of metastatic breast cancer. Am. J. Cancer Res. 10, 211-223 (2020).

40. van der Horst, G. et al. Targeting of alpha-v integrins reduces malignancy of bladder carcinoma. PLoS One 9, e108464 (2014).

41. de Gramont, A., Faivre, S. \& Raymond, E. Novel TGF-beta inhibitors ready for prime time in onco-immunology. Oncoimmunology 6, e1257453 (2017).

42. Martin, C. J. et al. Selective inhibition of TGFbetal activation overcomes primary resistance to checkpoint blockade therapy by altering tumor immune landscape. Sci. Transl. Med. 12, eaay8456 (2020).

43. Vannini, A. et al. alphavbeta3-integrin regulates PD-L1 expression and is involved in cancer immune evasion. Proc. Natl Acad. Sci. USA 116 20141-20150 (2019)

44. Mariathasan, S. et al. TGFbeta attenuates tumour response to PD-L1 blockade by contributing to exclusion of T cells. Nature 554, 544-548 (2018).

45. Ravi, R. et al. Bifunctional immune checkpoint-targeted antibody-ligand traps that simultaneously disable TGFbeta enhance the efficacy of cancer immunotherapy. Nat. Commun. 9, 741 (2018).

46. Lan, Y. et al. Enhanced preclinical antitumor activity of M7824, a bifunctional fusion protein simultaneously targeting PD-L1 and TGF-beta. Sci. Transl. Med. 10, eaan5488 (2018)

47. Mokrani, M., Klibi, J., Bluteau, D., Bismuth, G., \& Mami-Chouaib, F. Smad and NFAT pathways cooperate to induce CD103 expression in human CD8 T lymphocytes. J. Immunol. 192, 2471-2479 (2014).

48. Franciszkiewicz, K. et al. Intratumoral induction of CD103 triggers tumorspecific CTL function and CCR5-dependent T-cell retention. Cancer Res. 69, 6249-6255 (2009)

49. Anz, D. et al. CD103 is a hallmark of tumor-infiltrating regulatory T cells. Int J. Cancer 129, 2417-2426 (2011).

50. Gabriely, G. et al. Targeting latency-associated peptide promotes antitumor immunity. Sci. Immunol. 2, eaaj173 (2017). 
51. Stockis, J. et al. Blocking immunosuppression by human Tregs in vivo with antibodies targeting integrin alphaVbeta8. Proc. Natl Acad. Sci. USA 114 E10161-E10168 (2017).

52. Worthington, J. J. et al. Integrin alphavbeta8-mediated TGF-beta activation by effector regulatory $\mathrm{T}$ cells is essential for suppression of T-cell-mediated inflammation. Immunity 42, 903-915 (2015).

53. Paidassi, H. et al. Preferential expression of integrin alphavbeta8 promotes generation of regulatory $\mathrm{T}$ cells by mouse $\mathrm{CD} 103+$ dendritic cells. Gastroenterology 141, 1813-1820 (2011).

54. Boutet, M. et al. TGFbeta signaling intersects with CD103 integrin signaling to promote T-lymphocyte accumulation and antitumor activity in the lung tumor microenvironment. Cancer Res. 76, 1757-1769 (2016).

55. Sandoval, F. et al. Mucosal imprinting of vaccine-induced CD8(+) T cells is crucial to inhibit the growth of mucosal tumors. Sci. Transl. Med. 5, 172ra120 (2013).

56. Cepek, K. L. et al. Adhesion between epithelial cells and T lymphocytes mediated by E-cadherin and the alpha E beta 7 integrin. Nature 372, 190-193 (1994).

57. Zhang, N. \& Bevan, M. J. Transforming growth factor-beta signaling controls the formation and maintenance of gut-resident memory $\mathrm{T}$ cells by regulating migration and retention. Immunity 39, 687-696 (2013)

58. Mohammed, J. et al. Stromal cells control the epithelial residence of DCs and memory $\mathrm{T}$ cells by regulated activation of TGF-beta. Nat. Immunol. 17, 414-421 (2016).

59. Hothorn, T. \& Lausen, B. On the exact distribution of maximally selected rank statistics. Comput. Stat. Data Anal. 43, 121-137 (2003).

60. Gyorffy, B., Surowiak, P., Budczies, J. \& Lanczky, A. Online survival analysis software to assess the prognostic value of biomarkers using transcriptomic data in non-small-cell lung cancer. PLoS One 8, e82241 (2013).

61. Seo, S. R. et al. The novel E3 ubiquitin ligase Tiull associates with TGIF to target Smad2 for degradation. EMBO J. 23, 3780-3792 (2004).

\section{Acknowledgements}

We thank Yann Lecluse, Philippe Rameau and Valérie Rouffiac from the cytometry facility (Plateforme d'Imagerie-Cytométrie) and Francesco Baschieri from Endocytosis cytoskeleton and cell migration Unit, Gustave Roussy, for their help with flow cytometry and imaging. We also thank Virginie Marty and Nicolas Signolle from the platform of histocytopathology (Centre de Ressources Biologiques) of Gustave Roussy for their help with lung tumour specimens and IHC. We are grateful to Jihène Lahmar-Bach-Hamba, Jordi Remon-Masip, José-Carlos Benitez-Montanez, Maud Ngocamus, and Claudio Nicotra from the Department of Medical Oncology of Gustave Roussy for their help with establishing patient tumour cohorts. We are also grateful to Elodie Voilin for her technical assistance. This work was supported by grants from the "Association pour la Recherche sur le Cancer” (ARC; Grant numbers: PJA20161204720, SIGN'IT20181007792 and PJA 20181208049); the French "Institut National du Cancer" (INCa; PLBIO016-080 Grant number 10557); "Ligue Contre le Cancer" (Comité des Yvelines, Grant number 9FI12414QLCZ and Comité du Val de Marne, 2019) and Bristol-Myers Squibb (BMS, France; Grant number CA209-942). S.C. was supported by grants from "Groupement des Entreprises Françaises dans la Lutte contre le Cancer” (GEFLUC; Grant number 2016R16180LL) and Cancéropôle Ile-De-France (IDF; Grant number 2020-1-EMERGS-28), and was a recipient of a fellowship from FRM (Fondation Recherche Medicale), Gustave Roussy (SIRIC-SOCRATE), INCa (PLBIO016-080 Grant number 10557) and ARC
(SIGN'IT20181007792). I.M. was a recipient of a fellowship from the Ligue National Contre le Cancer and INCa (PLBIO016-080).

\section{Author contributions}

I.M. and F.M.C. concepted the present study. I.M., S.C. and F.M.C. developed the methodology. The acquisition of data (providing animals, acquiring, and managing patients, providing facilities, etc.) has been performed by I.M., J.A., L.M., I.D., D.P., B.B. and F.M.C. The analysis and interpretation of data (e.g., statistical analysis, biostatistics, computational analysis) was done by I.M., E.A. and F.M.C. I.M., S.C. and F.M.C. wrote, reviewed, and/or revised the paper. The administrative, technical and material support (i.e., reporting and organizing data, constructing databases) was carried out by I.M., J.A., S.C., L.G., G.G., V.D.M., N.T. and F.M.C. F.M.C. supervised the study.

\section{Competing interests}

B.B.'s sponsored research at Gustave Roussy Cancer Centre: Abbvie, Amgen, AstraZeneca, BeiGene, Blueprint Medicines, BMS, Boehringer Ingelheim, Celgene, Cristal Therapeutics, Daiichi-Sankyo, Eli Lilly, GSK, Ignyta, IPSEN, Inivata, Janssen, Merck KGaA, MSD, Nektar, Onxeo, OSE immunotherapeutics, Pfizer, Pharma Mar, RocheGenentech, Sanofi, Servier, Spectrum Pharmaceuticals, Takeda, Tiziana Pharma, Tolero Pharmaceuticals. All other authors declare no competing interests.

\section{Additional information}

Supplementary information The online version contains supplementary material available at https://doi.org/10.1038/s41467-021-25322-y.

Correspondence and requests for materials should be addressed to F.M-C.

Peer review information Nature Communications thanks Mark Travis and the other, anonymous, reviewer(s) for their contribution to the peer review of this work. Peer reviewer reports are available.

Reprints and permission information is available at http://www.nature.com/reprints

Publisher's note Springer Nature remains neutral with regard to jurisdictional claims in published maps and institutional affiliations.

pen Access This article is licensed under a Creative Commons Attribution 4.0 International License, which permits use, sharing, adaptation, distribution and reproduction in any medium or format, as long as you give appropriate credit to the original author(s) and the source, provide a link to the Creative Commons license, and indicate if changes were made. The images or other third party material in this article are included in the article's Creative Commons license, unless indicated otherwise in a credit line to the material. If material is not included in the article's Creative Commons license and your intended use is not permitted by statutory regulation or exceeds the permitted use, you will need to obtain permission directly from the copyright holder. To view a copy of this license, visit http://creativecommons.org/ licenses/by/4.0/.

(C) The Author(s) 2021 